NASA/TM-2006-214467/REV1

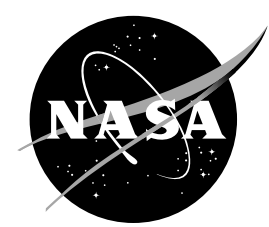

\title{
Development and Evaluation of TiAl Sheet Structures for Hypersonic Applications
}

S.L. Draper, D. Krause, and B. Lerch

Glenn Research Center, Cleveland, Ohio

I.E. Locci

University of Toledo, Toledo, Ohio

B. Doehnert and R. Nigam

Pratt \& Whitney, West Palm Beach, Florida

G. Das

Pratt \& Whitney, East Hartford, Connecticut

P. Sickles

Engineering Evaluation and Design, Florence, Kentucky

B. Tabernig, N. Reger, and K. Rissbacher

Plansee AG, Reutte, Austria 


\section{NASA STI Program . . . in Profile}

Since its founding, NASA has been dedicated to the advancement of aeronautics and space science. The NASA Scientific and Technical Information (STI) program plays a key part in helping NASA maintain this important role.

The NASA STI Program operates under the auspices of the Agency Chief Information Officer. It collects, organizes, provides for archiving, and disseminates NASA's STI. The NASA STI program provides access to the NASA Aeronautics and Space Database and its public interface, the NASA Technical Reports Server, thus providing one of the largest collections of aeronautical and space science STI in the world. Results are published in both non-NASA channels and by NASA in the NASA STI Report Series, which includes the following report types:

- TECHNICAL PUBLICATION. Reports of completed research or a major significant phase of research that present the results of NASA programs and include extensive data or theoretical analysis. Includes compilations of significant scientific and technical data and information deemed to be of continuing reference value. NASA counterpart of peer-reviewed formal professional papers but has less stringent limitations on manuscript length and extent of graphic presentations.

- TECHNICAL MEMORANDUM. Scientific and technical findings that are preliminary or of specialized interest, e.g., quick release reports, working papers, and bibliographies that contain minimal annotation. Does not contain extensive analysis.

- CONTRACTOR REPORT. Scientific and technical findings by NASA-sponsored contractors and grantees.
- CONFERENCE PUBLICATION. Collected papers from scientific and technical conferences, symposia, seminars, or other meetings sponsored or cosponsored by NASA.

- SPECIAL PUBLICATION. Scientific, technical, or historical information from NASA programs, projects, and missions, often concerned with subjects having substantial public interest.

- TECHNICAL TRANSLATION. Englishlanguage translations of foreign scientific and technical material pertinent to NASA's mission.

Specialized services also include creating custom thesauri, building customized databases, organizing and publishing research results.

For more information about the NASA STI program, see the following:

- Access the NASA STI program home page at http://www.sti.nasa.gov

- E-mail your question via the Internet to help@sti.nasa.gov

- Fax your question to the NASA STI Help Desk at 301-621-0134

- Telephone the NASA STI Help Desk at 301-621-0390

- Write to:

NASA STI Help Desk

NASA Center for AeroSpace Information 7115 Standard Drive Hanover, MD 21076-1320 
NASA/TM—2006-214467/REV1

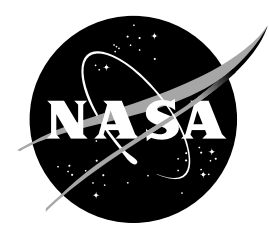

\section{Development and Evaluation of TiAl Sheet Structures for Hypersonic Applications}

S.L. Draper, D. Krause, and B. Lerch

Glenn Research Center, Cleveland, Ohio

I.E. Locci

University of Toledo, Toledo, Ohio

B. Doehnert and R. Nigam

Pratt \& Whitney, West Palm Beach, Florida

G. Das

Pratt \& Whitney, East Hartford, Connecticut

P. Sickles

Engineering Evaluation and Design, Florence, Kentucky

B. Tabernig, N. Reger, and K. Rissbacher

Plansee AG, Reutte, Austria

National Aeronautics and

Space Administration

Glenn Research Center

Cleveland, Ohio 44135 


\section{Document Change History}

This printing, numbered as NASA/TM-2006-214467/REV1, October 2007, replaces the previous version, NASA/TM-2006214467, November 2006, in its entirety. It contains the following changes:

Page 3, last 5 lines read:

Bolted clevis samples determined the stress concentration at the subelement bolt holes and were fabricated by brazing three TiAl sheets, one on top of the other, figure 1(c). The three sheets included two 1-mm sheets and a 6.4-mm-thick plate. A test fixture was designed and machined to test the bolted clevis samples in an in-plane biaxial load frame. The bolted clevis samples were tested at room temperature using stroke control with a linear displacement ramp of $2.5 \times 10^{-4} \mathrm{~cm} / \mathrm{s}$.

Trade names and trademarks are used in this report for identification only. Their usage does not constitute an official endorsement, either expressed or implied, by the National Aeronautics and Space Administration.

Level of Review: This material has been technically reviewed by technical management.

Available from

NASA Center for Aerospace Information 7115 Standard Drive

Hanover, MD 21076-1320
National Technical Information Service 5285 Port Royal Road Springfield, VA 22161 


\title{
Development and Evaluation of TiAl Sheet Structures for Hypersonic Applications
}

\author{
S.L. Draper, D. Krause, and B. Lerch \\ National Aeronautics and Space Administration \\ Glenn Research Center \\ Cleveland, Ohio 44135 \\ I.E. Locci \\ University of Toledo \\ Toledo, Ohio 43606 \\ B. Doehnert and R. Nigam \\ Pratt \& Whitney \\ West Palm Beach, Florida 33410 \\ G. Das \\ Pratt \& Whitney \\ East Hartford, Connecticut 06108 \\ P. Sickles \\ Engineering Evaluation and Design \\ Florence, Kentucky 41042 \\ B. Tabernig, N. Reger, and K. Rissbacher \\ Plansee AG \\ Reutte, Austria
}

\begin{abstract}
A cooperative program between the National Aeronautics and Space Administration (NASA), the Austrian Space Agency (ASA), Pratt \& Whitney, Engineering Evaluation and Design, and Plansee AG was undertaken to determine the feasibility of achieving significant weight reduction of hypersonic propulsion system structures through the utilization of TiAl. A trade study defined the weight reduction potential of TiAl technologies as 25 to 35 percent compared to the baseline Ni-base superalloy for a stiffener structure in an inlet, combustor, and nozzle section of a hypersonic scramjet engine (ref. 1). A scramjet engine inlet cowl flap was designed, along with a representative subelement, using design practices unique to TiAl. A subelement was fabricated and tested to assess fabricability and structural performance and validate the design system. The TiAl alloy selected was Plansee's third generation alloy Gamma Met PX (Plansee AG), a high temperature, high strength $\gamma$-TiAl alloy with high Nb content (refs. 2 and 3). Characterization of Gamma Met PX sheet, including tensile, creep, and fatigue testing was performed. Additionally, design-specific coupons were fabricated and tested in order to improve subelement test predictions. Based on the sheet characterization and results of the coupon tests, the subelement failure location and failure load were accurately predicted.
\end{abstract}

\section{Introduction}

Gamma TiAl is an attractive candidate for structural aerospace applications due to its high strength, low density, and good oxidation resistance (refs. 4 and 5). Hypersonic vehicles have aggressive thrust/weight targets and high operating temperatures. Significant weight benefits could be realized by 
utilizing $\gamma$-TiAl for large, static structures in a hypersonic engine. However, design methodology, manufacturing techniques, finite element analysis, and material characterization need to be further developed before TiAl can be implemented into structural components. This program aimed to further the technology readiness of Gamma TiAl for structural applications. Gamma Met PX (GMPX), a highstrength TiAl based on the TNB alloys developed by GKSS Research Center, was selected due to its excellent mechanical properties. The microstructure and mechanical properties of several GMPX sheets were characterized. A scramjet inlet flap subelement was designed and fabricated from GMPX sheet and plate. Coupons, designed to enable the accurate prediction of subelement behavior, were also fabricated and tested. Using the mechanical property database generated and the results of the configuration-specific coupon tests, the subelement failure location and load were accurately predicted using ANSYS.

\section{Materials and Procedures}

\section{A. Sheet Characterization}

Five of Plansee's Gamma Met PX (GMPX) sheets were microstructurally examined by optical, scanning (SEM), and transmission electron microscopy (TEM). Four of the sheets were $1 \mathrm{~mm}$ thick and one was $1.5 \mathrm{~mm}$ thick. All sheets were characterized in the as-received condition. Inductively coupled plasma (ICP) was used to analyze the chemical composition of the sheets.

Tensile, fatigue, and creep specimens were machined in both the longitudinal and transverse direction from sheets using electrodischarge machining (EDM). Since TiAl is susceptible to EDM damage, the cut surfaces had to be polished by hand or low stress ground in order to remove any pitting. Electrolysis free EDM resulted in the least amount of EDM pitting and was used for the tensile and some of the fatigue samples. Initial tensile samples were polished by hand to 600 grit; however, sufficient material was not removed to eliminate failures occurring at residual EDM damage. Only data from samples which failed in the gage section is reported and all error bands represent 95 percent confidence intervals. Subsequent tensile tests used the fatigue specimen design which had a large transition radius to minimize stress concentrations and enable automated grinding of the edges. Tensile samples were tested from 23 to $800{ }^{\circ} \mathrm{C}$ using a strain-rate control of $1 \times 10^{-4} \mathrm{~s}^{-1}$. Fatigue tests were run in load-control with a tensiontension $(\mathrm{R} \sigma=0.05)$ cycle. Tests were conducted at various temperatures from 23 to $800{ }^{\circ} \mathrm{C}$ at a frequency of $0.5 \mathrm{~Hz}$. The fatigue tests were conducted at a beginning stress level and cycled to approximately $10^{6}$ cycles. If the specimen had not failed, the maximum stress was increased by approximately $14 \mathrm{MPa}$ and cycling continued for another $10^{6}$ cycles. This process was repeated until the specimen failed. This "step testing" has been shown to reliably provide failure data on gamma TiAl samples (ref. 6). Of the 13 loadcontrolled tests, 10 samples failed on the first load block and therefore were not step tests. For the three specimens receiving steps, the fatigue life was taken as the number of cycles in the last step only and the previous steps were deemed inconsequential to the life. A few samples were tested in strain-control under fully-reversed loading, using anti-buckling guides, to give some idea of their response under this test mode. At room temperature, a smaller sample size was used and tested without buckling guides in an unconstrained fashion. All fully-reversed tests were conducted at a constant strain range and at a strain rate of $1 \times 10^{-4} \mathrm{~s}^{-1}$. Creep testing was performed on $114 \mathrm{~mm}$ long, reduced gage samples at $760{ }^{\circ} \mathrm{C}$. Creep strain was determined as a function of time via an extensometer that was pinned to the shoulders of the specimen, above and below the gage section. All the relative motion of the extensometer was assumed to have occurred in the gage section.

\section{B. Configuration-Specific Coupon Testing}

Brazing was selected as the joining technique for the subelement primarily due to schedule constraints. Consequently, all of the configuration specific test coupons were joined by brazing. The brazing technique is proprietary to Plansee such that the details can not be given, however, it was performed above $1000{ }^{\circ} \mathrm{C}$ in a high vacuum furnace with a slow heat up and cool down. During the 
fabrication method development, Plansee appraised the strength of brazed round test bars by brazing two round bars together, end-to-end, and tensile testing across the braze. The braze strength of a Ti-Ni braze alloy was approximately 330 to $450 \mathrm{MPa}$ at both 23 and $700{ }^{\circ} \mathrm{C}$. While this was comparable to the braze strength obtained in a previous program on Gamma Met 100 (ref. 7), it is considerably lower than the raw material capability of 750 to $1050 \mathrm{MPa}$. The Ti-Ni braze was selected based on obtaining the best balance of tensile strength and oxidation resistance of brazed material. Sheet tensile samples were put through a braze thermal cycle and subsequently tensile tested to determine the effects of the braze thermal cycle on material tensile properties. While the strength of the as-received and exposed samples were equivalent, the plastic strain to failure decreased by 50 percent due to the braze thermal exposure. GMPX has been shown to embrittle due to oxygen penetration during high temperature exposures (ref. 8). While the braze was performed under high vacuum, it is possible that sufficient oxygen was present to diffuse into the near-surface microstructure and decrease the ductility of the alloy.

To better understand the subelement performance when loaded, four configuration-specific coupons were defined, fabricated, and structurally tested. The specimens were designed to assess key configuration features. The results were used to define the capabilities of the material and structure, especially at stress concentration locations such as steps, bolts, and brazed joints and were incorporated in the pre-test and post-test subelement strength predictions. Gamma Met PX sheet and plate were brazed together using a Ti-Ni braze alloy to fabricate the four types of coupons (braze shear, stepped tensile, bolted clevis, and braze peel samples) shown in figure 1.

A braze shear test method, developed under a previous program (ref. 7), was utilized to test the Gamma TiAl braze joint. The test sample consisted of two pieces of material brazed together as shown in figure 1(a). The braze shear samples were tested at 23,371 , and $649^{\circ} \mathrm{C}$ using a constant crosshead speed of $2.54 \times 10^{-4} \mathrm{~cm} / \mathrm{s}$. Stepped tensile specimens were used to determine the stress concentration in the subelement where two sheets were brazed together and one of the sheets is discontinued, creating a step, figure 1(b). The stepped tensile specimens were fabricated by brazing either a $1 \mathrm{~mm}$ sheet or a $6.4 \mathrm{~mm}$ plate on both ends of a $1 \mathrm{~mm}$ thick sheet which was $140 \mathrm{~mm}$ long, figure 1(b). The stepped tensile specimens were tested at 23 and $600{ }^{\circ} \mathrm{C}$. Only the samples fabricated with the $6.4 \mathrm{~mm}$ thick plate were tested at elevated temperature, with thermocouples placed at the center and at $6 \mathrm{~mm}$ intervals. Bolted clevis samples determined the stress concentration at the subelement bolt holes and were fabricated by brazing three TiAl sheets, one on top of the other, figure 1(c). The three sheets included two 1-mm sheets and a 6.4-mm-thick plate. A test fixture was designed and machined to test the bolted clevis samples in an in-plane biaxial load frame. The bolted clevis samples were tested at room temperature using stroke

(a)
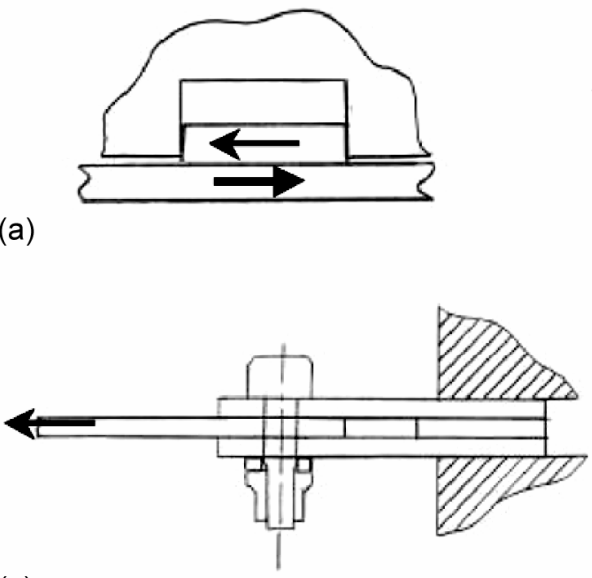

(c)

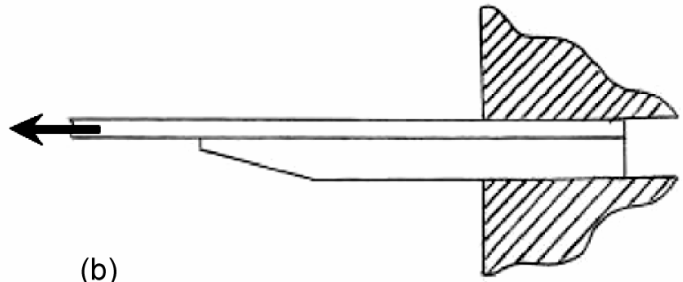

(b)

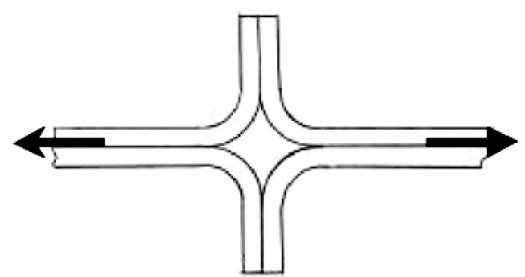

(d)

Figure 1.-Four configuration-specific coupons were defined, fabricated, and structurally tested to help predict the subelement failure strength and location. (a) Braze shear. (b) Stepped tensile. (c) Bolted clevis. (d) Braze peel. 
control with a linear displacement ramp of $2.5 \times 10^{-4} \mathrm{~cm} / \mathrm{s}$. Brazed peel samples, with a configuration shown in figure 1(d), were processed in a one-step brazing cycle with the long aspect laying flat and the short dimension undergoing a vertical braze. The braze peel samples were tested at either 23 or $760{ }^{\circ} \mathrm{C}$ with a constant crosshead speed of $2.54 \times 10^{-4} \mathrm{~cm} / \mathrm{s}$. Strain gages were applied approximately $1.2 \mathrm{~cm}$ from the center on the room temperature samples, centered in the width and an axial extensometer measured strain over the middle $1.2 \mathrm{~cm}$ of the sample.

\section{Subelement Design and Fabrication}

Based on the inlet flap design, a hinge beam load test article subelement was designed that would demonstrate basic structure fabricability, as well as provide relevant mechanical testing. This subelement is a C-channel reinforced sandwich structure with hinge attachments at each end. Plansee fabricated three subelements using identical process and all three turned out to be of similar quality, figure 2. Many details of the fabrication process are considered to be proprietary by Plansee and thus only an overview of the process is given. The subelement was constructed using a variety of sheet and plate material that was fixtured and brazed using a Ti-Ni braze in a single braze cycle. Each subelement was pulse-echo ultrasonically inspected using four scans from top to bottom to determine braze coverage and quality. Overall, the successive comparison of the scans revealed good braze coverage with minimal ultrasonic indication corresponding to a good bond integrity for the first subelement. The other two subelements had some indication of a poor bond between the facesheet and the doublers and some indication of a poor bond at the drilling areas of the holes.

\section{Subelement Test}

The inlet flap subelement test was designed to simulate the limiting load condition during the inlet flap operation, specifically a cantilever load at the flap hinge. A three-point bend test was specified, with a moment-to-shear load ratio of $0.508 \mathrm{~m}$, representative of the inlet flap design value. Tooling and testing loading points for the subelement three-point bend test were designed to produce a $0.508 \mathrm{~m}$ load ratio at the predicted critical location, figure 3 . The tooling bars were custom machined and shimmed such that they engaged the subelement flanges with little to no clearance and would compensate for subelement manufacturing tolerances. Threaded holes in each bar had locations precision machined so the bolt shoulders would effectively shear dial the subelement to the bars at all 16 attachment locations nearly simultaneously. This would provide the most uniform bolt load distribution possible during the test. To

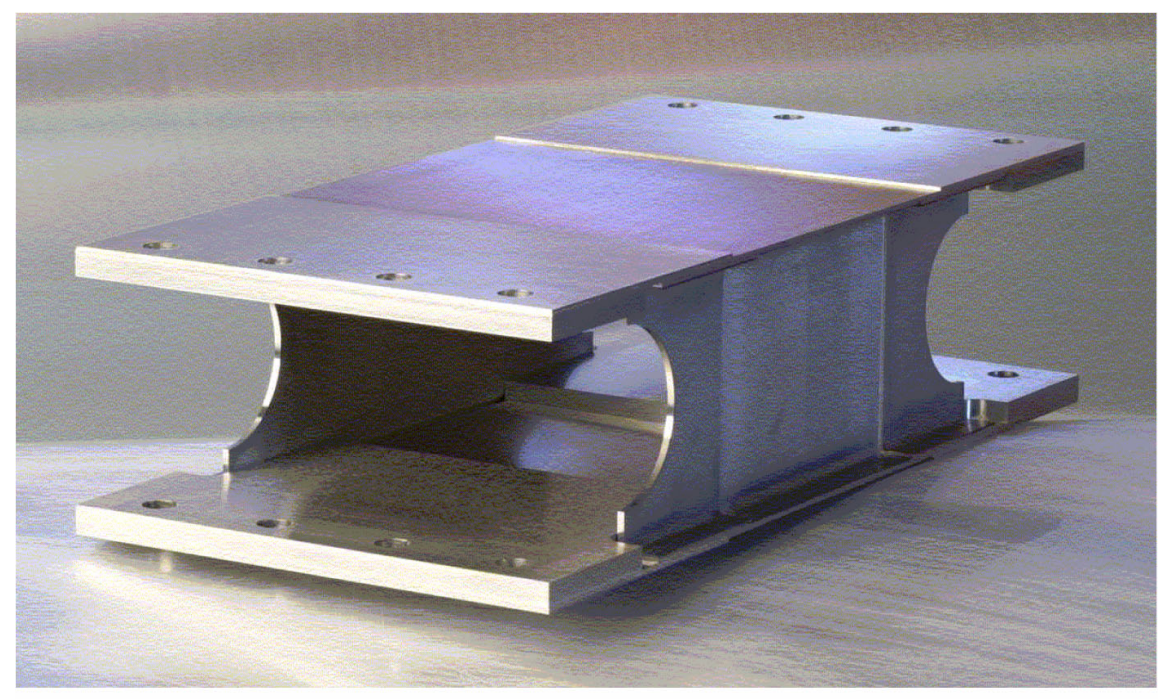

Figure 2.-One of three Gamma Met PX subelements fabricated by Plansee AG. 
further minimize the possibility of load localizations skewing test results, the load was applied to the tooling, not directly to the subelement. Four axial strain gages located centered along the width of the Cchannel flanges and one axial strain gage located at the center of the subelement face sheet were intended for analysis calibration and determining any asymmetric structural behavior during subelement loading, figure 4. Front surfaces of the subelement were coated with a high contrast random painted pattern for use in two-dimensional speckle pattern interferometry (SPI) system. This method employs pattern recognition of the painted area of the structure using digital still images taken between the unloaded and loaded conditions. By interpolation, test specimen displacements in two dimensions are resolved to a distance equivalent to 1/50 of a pixel width; strains then are calculated from these displacements. Piezo-electric acoustic emission sensors were utilized as a means of detecting cracking noise during the test. A dial indicator was placed at the upper sheet center to verify the assembly vertical displacement. A thin rubber strip was placed along the load line between the load frame and the tooling to allow a more uniform load distribution across the specimen width.

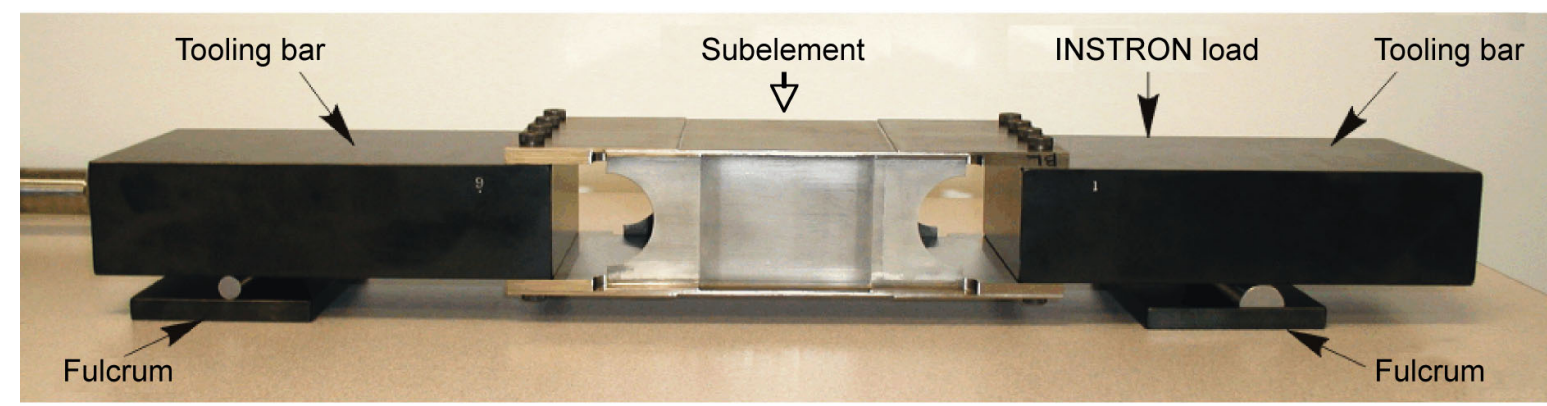

Figure 3.-The subelement three-point bend assembly showing location of applied load.

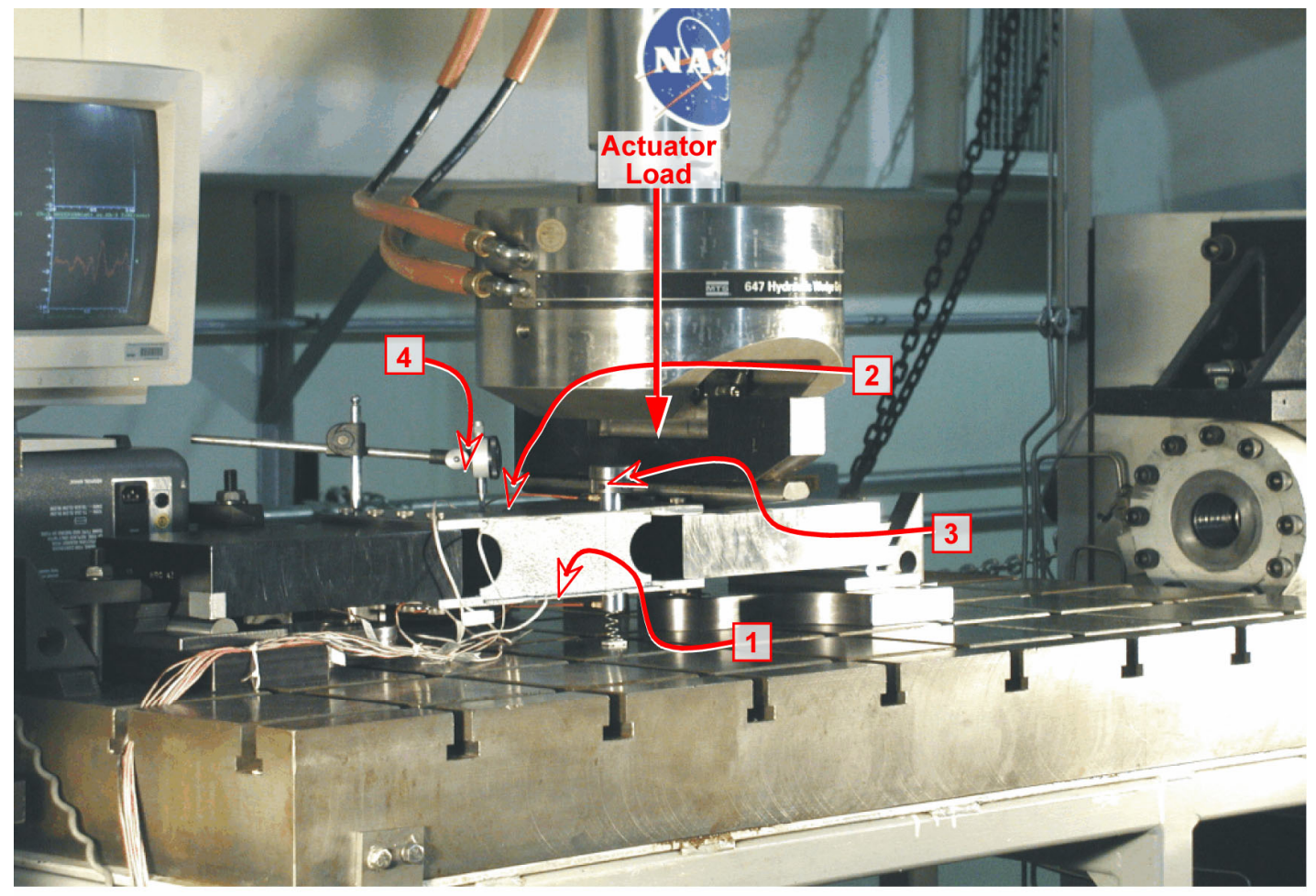

Figure 4.-Subelement 3-point bend test setup with the following instrumentation. (1) Four axial strain gages centered along length and width of the C-channel flanges. (2) One axial strain gage located at the center of the subelement face sheet. (3) Acoustic emission sensors. (4) Dial indicator at the upper sheet center. 

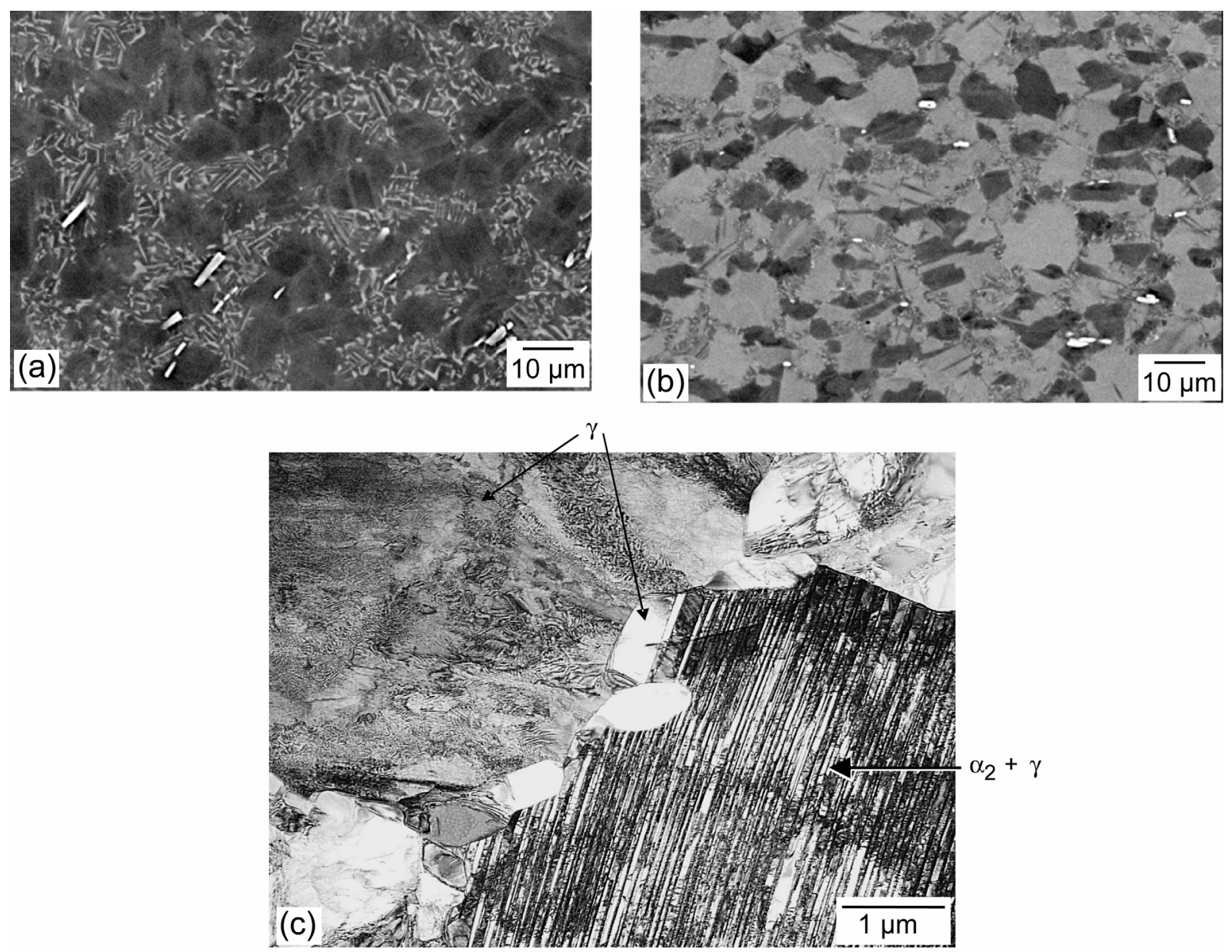

Figure 5.-(a) Typical SEM micrograph of Gamma Met PX (sheet GMPX B-1 mm) showing a duplex microstructure with a coarse $\alpha_{2} / \gamma$ platelets decorating $\gamma$-TiAl (dark phase) grains. The bright elongated particles are (Ti, Nb)-borides. (b) Two GMPX sheets (GMPX E-1.5 mm and F-1 mm) had equiaxed $\gamma-$ TiAl (dark phase) and colonies of $\gamma-\mathrm{TiAl}$ and $\alpha_{2}-\mathrm{Ti} 3 \mathrm{Al}$ lamellae which had such a small spacing that (c) transmission electron microscopy was required to resolve the $\alpha_{2} / \gamma$ spacing.

\section{Results and Discussion}

\section{A. Sheet Characterization}

Five sheets of Gamma Met PX and one sheet of Gamma Met 100 (a second generation alloy with Cr, $\mathrm{Nb}$ and Ta additions) were characterized. The chemical composition of all five GMPX sheets were within satisfactory statistical variation, table I. The GMPX sheets had a duplex microstructure consisting of equiaxed $\gamma$-grains with a grain size of approximately $15 \mu \mathrm{m}$ and lamellar colonies of alternating layers of $\gamma$ and $\alpha_{2}$ platelets. Ti, Nb-borides aligned in the rolling direction were observed in all the GMPX sheets investigated. GMPX sheets B, C, and D had a duplex microstructure with a coarse lamellae of $\gamma / \alpha_{2}$ decorating the $\gamma$-grains as shown in figure 5(a). The other two GMPX sheets, E and F, had colonies of very fine spaced $\gamma / \alpha_{2}$ lamellae, which were difficult to resolve using the SEM, figure 5(b). Transmission electron microscopy was needed to resolve the fine microstructure of these colonies, figure 5(c). 
TABLE I.-CHEMICAL COMPOSITION OF GAMMA MET PX SHEETS (at.\%)

\begin{tabular}{|l|c|c|c|c|c|c|c|c|c|c|}
\hline Alloy/comp in at.\% & $\mathrm{Ti}$ & $\mathrm{Al}$ & $\mathrm{Cr}$ & $\mathrm{Nb}$ & $\mathrm{Fe}$ & $\mathrm{Ta}$ & $\mathrm{B}$ & $\mathrm{C}$ & $\mathrm{N}$ & $\mathrm{O}$ \\
\hline Gamma Met 100-A, 1 mm & 48.95 & 47 & 2.36 & 0.95 & 0.02 & 0.47 & 0.07 & 0.03 & 0.11 & 0.14 \\
\hline GMPX-B, $1 \mathrm{~mm}$ & 49.16 & 45.35 & 0.01 & 4.88 & 0.02 & ----- & 0.19 & 0.24 & 0.01 & 0.14 \\
\hline GMPX-C, $1 \mathrm{~mm}$ & 49.51 & 44.92 & 0.01 & 4.99 & 0.02 & ------ & 0.19 & 0.23 & 0.01 & 0.11 \\
\hline GMPX-D, $1 \mathrm{~mm}$ & 49.61 & 45.01 & 0.01 & 4.85 & 0.02 & ----- & 0.22 & 0.18 & 0.01 & 0.08 \\
\hline GMPX-E, $1.5 \mathrm{~mm}$ & 49.37 & 45.17 & 0.01 & 4.92 & 0.015 & ----- & 0.22 & 0.19 & 0.01 & 0.09 \\
\hline GMPX-F, $1 \mathrm{~mm}$ & 49.52 & 45.09 & 0.01 & 4.92 & 0.014 & ------ & 0.15 & 0.19 & 0.01 & 0.08 \\
\hline
\end{tabular}

GMPX sheets D, E, and F were used for the tensile testing, table II. Sheet GMPX-F, which was used for a $23{ }^{\circ} \mathrm{C}$ round-robin testing sequence between Plansee and NASA, had exceptionally high yield and ultimate tensile strength. This sheet had the duplex microstructure with the very fine lamellar spacing. Sheet GMPX-E had a similar microstructure, also with the very fine lamellar spacing, but had more typical yield and ultimate tensile strengths, table II. Therefore, it does not appear that fine lamellar spacing affected the tensile strengths. Comparing sheets GMPX-D $1 \mathrm{~mm}$ and GMPX-E $1.5 \mathrm{~mm}$, the $23{ }^{\circ} \mathrm{C}$ yield strength (YS) of the $1 \mathrm{~mm}$ sheet was significantly higher than the yield strength of the $1.5 \mathrm{~mm}$ sheet when the longitudinal and transverse data were grouped, but the ultimate tensile strength (UTS) and plastic elongations of the 1 and $1.5 \mathrm{~mm}$ thick sheet were statistically equivalent at 23,425 , and $600{ }^{\circ} \mathrm{C}$. Most likely the variation in yield strength is within normal variations observed between sheets and not a result of sheet thickness. While the $23^{\circ} \mathrm{C}$ YS was not significantly different between the longitudinal and transverse specimens of GMPX sheets D and E, the room temperature ultimate tensile strength and ductility were statistically higher for longitudinal samples compared to samples machined transverse to the rolling direction. The transverse specimens from the $1 \mathrm{~mm}$ thick sheet failed at microstructural inconsistencies leading to lower UTS and plastic elongation, figure 6(a). The samples machined transverse to the rolling direction initiated failure at what appears to be larger than typical grains. A chemical inhomogeneity was not detected by either backscatter electron imaging or energy dispersive spectrometry (EDS). The larger than normal grains ran parallel to the rolling direction in a stringer type fashion and were not detected on the fracture surfaces of specimens machined parallel to the rolling direction. A larger pool of data is required to determine the significance of rolling direction orientation on tensile properties for the $1.5 \mathrm{~mm}$ sheet.

TABLE II.-GAMMA MET PX SHEET TENSILE RESULTS

\begin{tabular}{|l|c|c|c|c|c|c|c|}
\hline \multicolumn{1}{|c|}{ Sheet } & $\begin{array}{c}\text { Thickness, } \\
\mathrm{mm}\end{array}$ & Orientation & $\begin{array}{c}\text { No. of } \\
\text { tests }\end{array}$ & $\begin{array}{c}\text { Temperature, } \\
{ }^{\circ} \mathrm{C}\end{array}$ & $\begin{array}{c}\text { YS } \pm 95 \% \text { C.I. } \\
\mathrm{MPa}\end{array}$ & $\begin{array}{c}\text { UTS } \pm 95 \% \text { C.I. } \\
\mathrm{MPa}\end{array}$ & $\begin{array}{c}\varepsilon_{\mathrm{p}} \pm 95 \% \text { C.I. } \\
\%\end{array}$ \\
\hline GMPX-F & 1 & $\mathrm{~L}$ & 16 & 23 & $1011 \pm 25$ & $1193 \pm 70$ & $0.67 \pm 0.14$ \\
\hline GMPX-D & 1 & L and T & 4 & 23 & $923 \pm 16$ & $975 \pm 58$ & $1.28 \pm 1.6$ \\
\hline GMPX-E & 1.5 & L and T & 5 & 23 & $870 \pm 23$ & $926 \pm 36$ & $1.03 \pm 0.17$ \\
\hline GMPX-D and E & $1,1.5$ & L and T & 9 & 23 & $893 \pm 24$ & $948 \pm 30$ & $1.14 \pm 0.48$ \\
\hline GMPX-D and E & $1,1.5$ & L and T & 7 & 425 & $796 \pm 60$ & $922 \pm 86$ & $2.05 \pm 0.73$ \\
\hline GMPX-D and E & $1,1.5$ & L and T & 7 & 600 & $774 \pm 59$ & $895 \pm 93$ & $1.72 \pm 0.83$ \\
\hline GMPX-E & 1.5 & L and T & 3 & 800 & $539 \pm 38$ & $611 \pm 40$ & $>9.5$ \\
\hline
\end{tabular}

Grouping the data from two sheets, D $(1 \mathrm{~mm})$ and $\mathrm{E}(1.5 \mathrm{~mm})$, the YS, UTS, and plastic elongation were analyzed as a function of temperature and a representative tensile curve for each temperature is plotted in figure 7. The YS was higher at RT than at $425^{\circ} \mathrm{C}$ with averages of 894 and $796 \mathrm{MPa}$, respectively. The YS remained constant from 425 to $600{ }^{\circ} \mathrm{C}$ and decreased to $539 \mathrm{MPa}$ at $800{ }^{\circ} \mathrm{C}$. The UTS was constant from room temperature to $600{ }^{\circ} \mathrm{C}$, averaging $924 \mathrm{MPa}$ and decreased to $611 \mathrm{MPa}$ at $800{ }^{\circ} \mathrm{C}$. The plastic elongation averaged 1.1 percent at room temperature and increased to 2.1 and 1.7 percent at 425 and $600{ }^{\circ} \mathrm{C}$, respectively. At $800{ }^{\circ} \mathrm{C}$, above the brittle to ductile transition temperature, the tests were stopped after reaching 10 percent strain. 

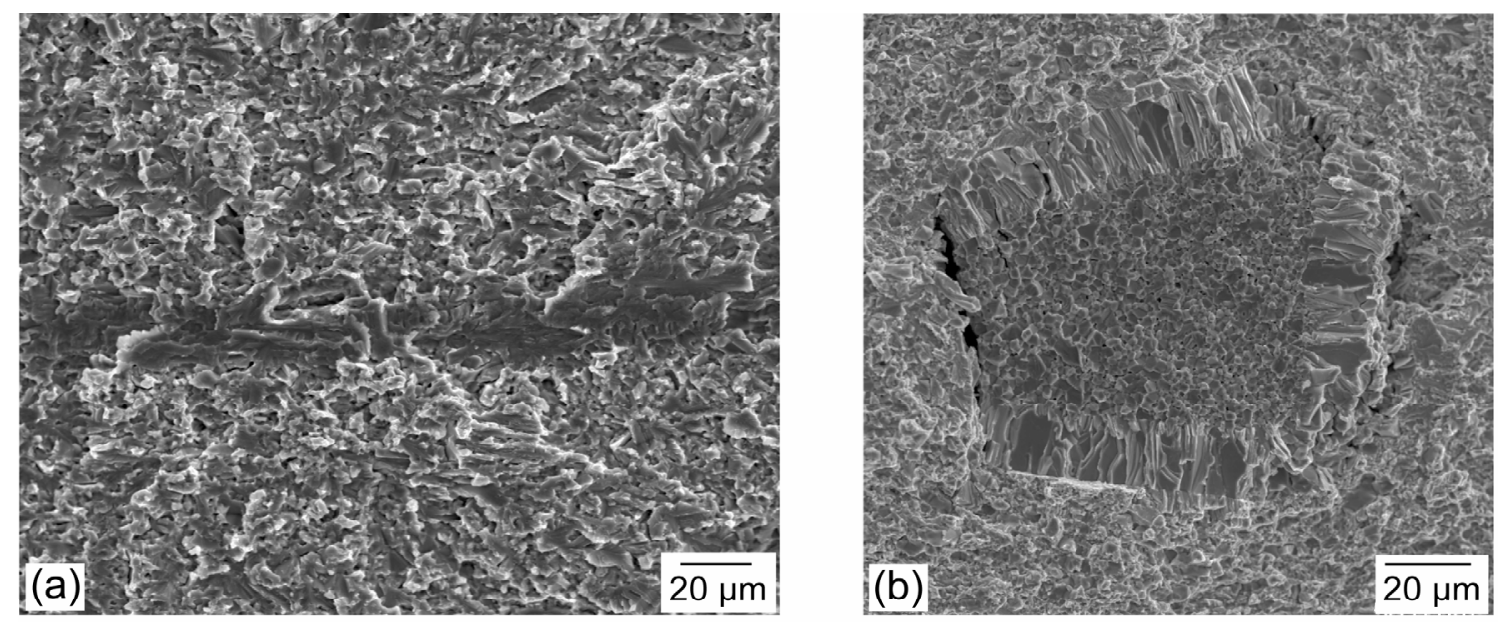

Figure 6.-(a) Large grains, elongated in the rolling direction, initiated failure in transgranular samples from sheet GMPX-D. Backscatter electron images and energy dispersive spectroscopy did not indicate any chemical inhomogeneity in the large grains. (b) A Ti-rich area initiated failure of a $600{ }^{\circ} \mathrm{C}$ transverse sample from sheet GMPX-E.

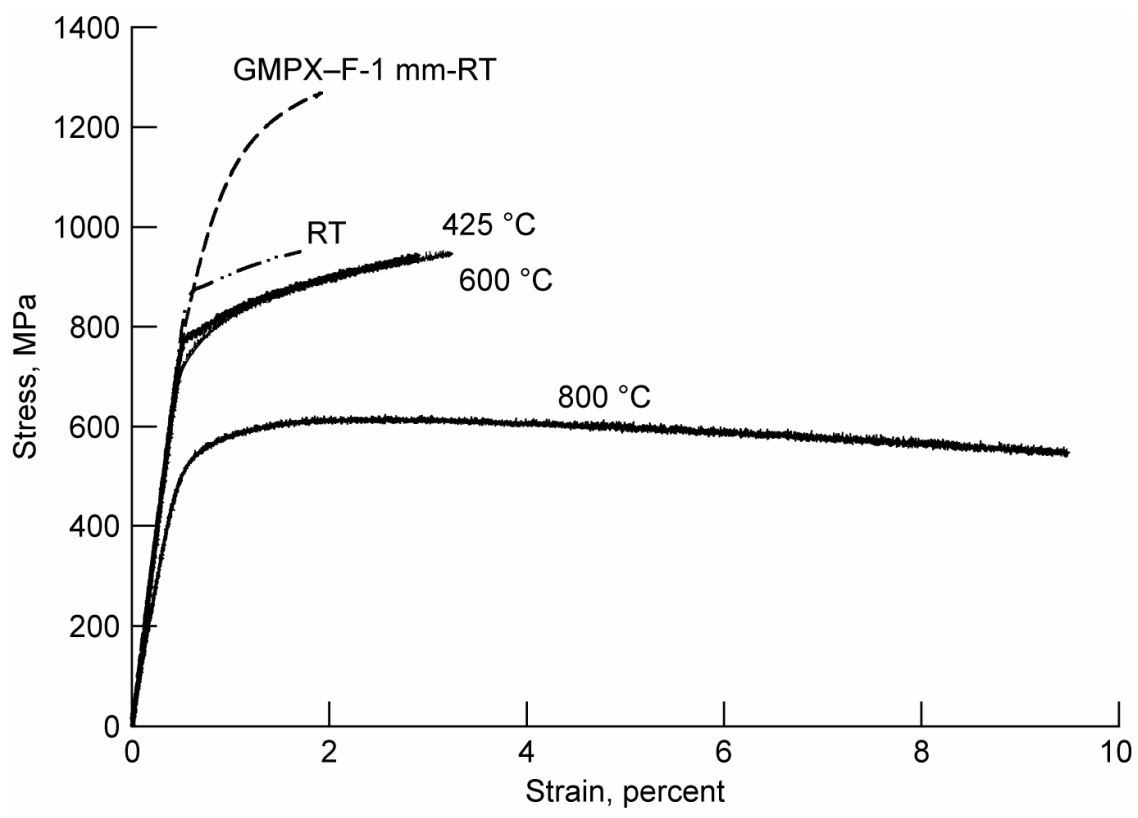

Figure 7.-Representative GMPX tensile curves at $23,425,600$, and $800{ }^{\circ} \mathrm{C}$. Sheet GMPX-F had a significantly higher strength than the other sheets tested.

The tensile fracture surfaces were examined in the SEM. As mentioned previously, the transverse samples from sheet GMPX-D (1 mm thick) failed at large grains that occurred parallel to the rolling direction, figure 6(a). Additionally, one transverse sample tested at $600{ }^{\circ} \mathrm{C}$ failed at a Ti-enriched area, figure 6(b). These microstructural inconsistencies did not lower the yield strengths but did tend to lower the UTS and ductility. River marks on the fracture surfaces of the $1 \mathrm{~mm}$ thick longitudinal samples indicated that fracture initiated at either surface or internal sites while the majority of the $1.5 \mathrm{~mm}$ thick sheet samples initiated fracture at the corner of the samples, figure 8(a). However, a few of the $1.5 \mathrm{~mm}$ thick samples also failed at internal sites with no obvious microstructural or machining defect, figure 8(b). The fracture surfaces exhibited a brittle fracture morphology with both transgranular and intergranular fracture. 

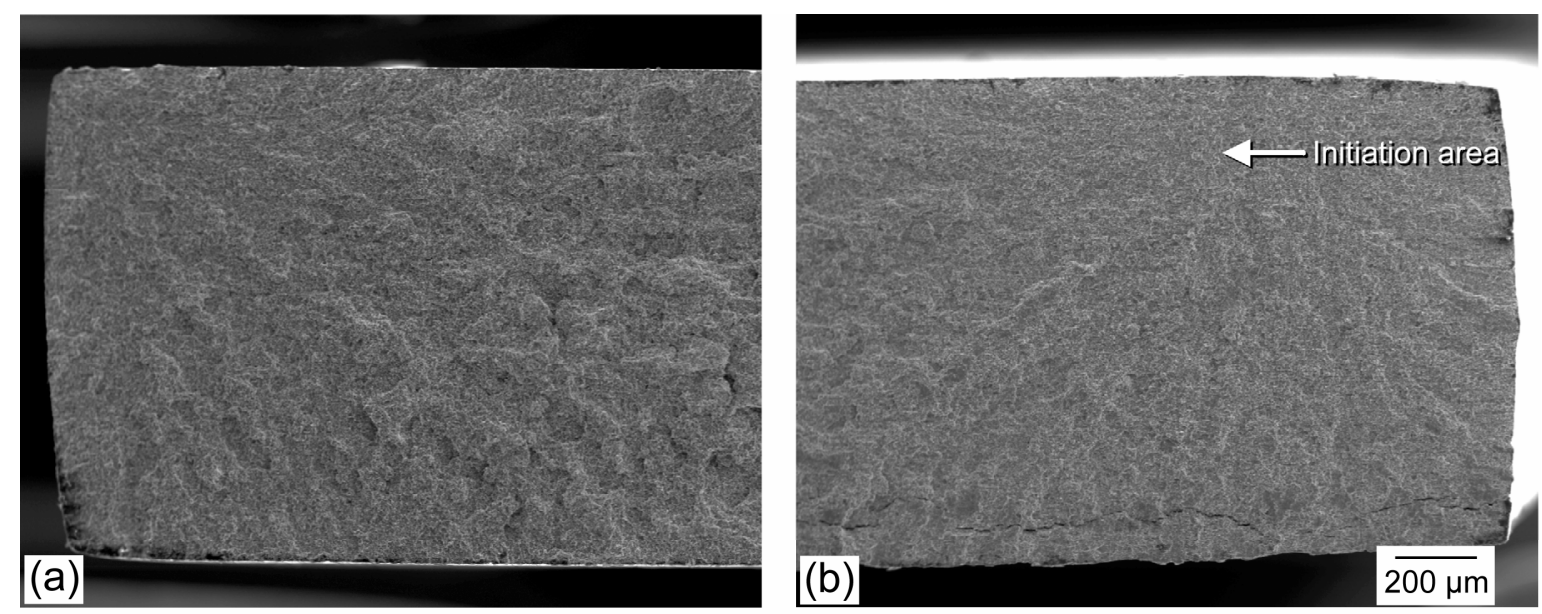

Figure 8.-Rivermarks on tensile fracture surfaces enabled identification of fracture initiation sites. (a) Failure initiated at corner and at (b) an internal site.

UTS,

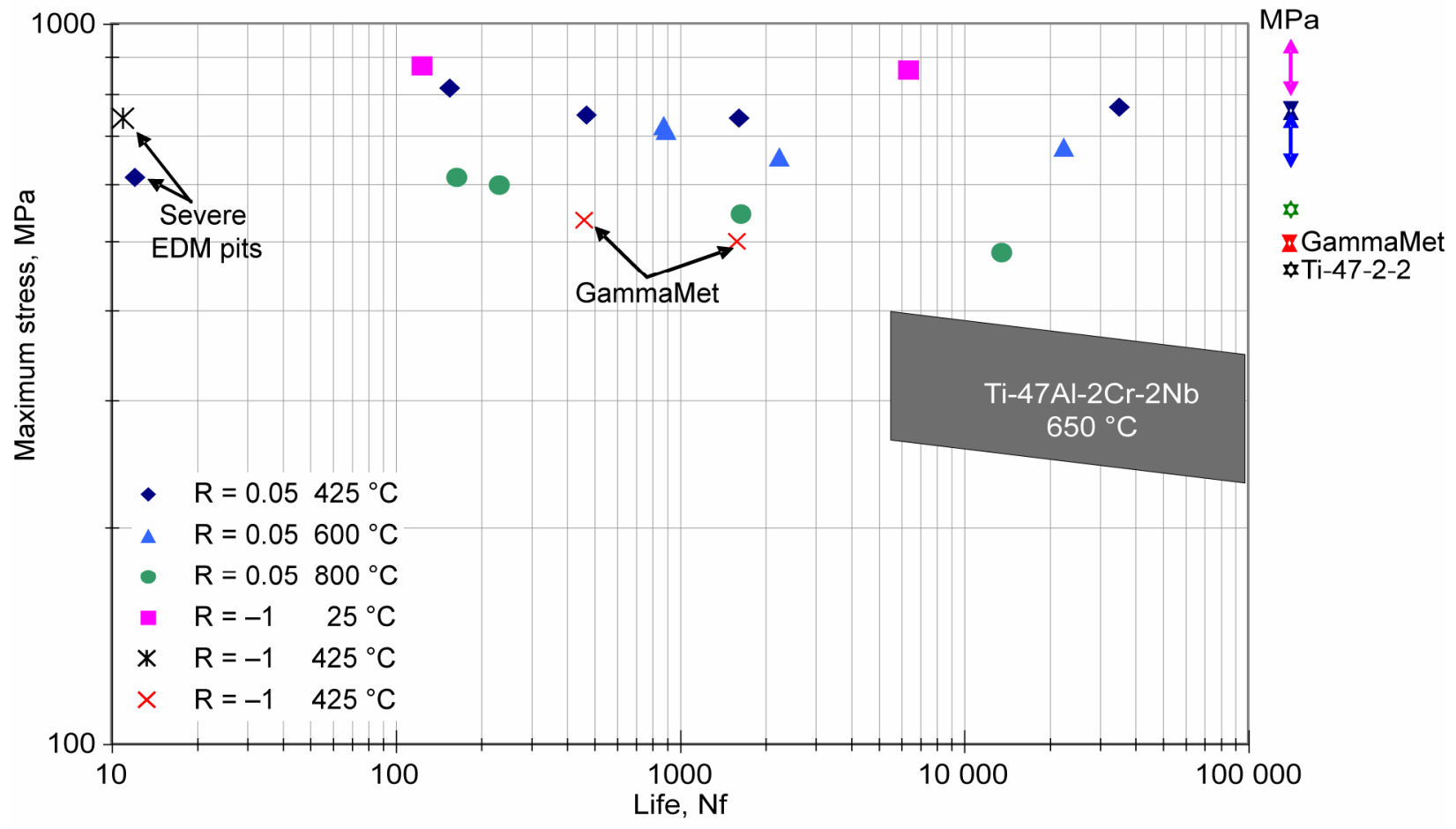

Figure 9.-Fatigue life for GMPX sheet compared to Gamma Met 100 and Ti-47Al-2Cr-2Nb.

The fatigue life data of GMPX sheet is shown in figure 9 as a function of maximum stress and compared to previous data on Gamma Met 100 and Ti-47Al-2Cr-2Nb. For the fully-reversed tests, the maximum stress is taken at half-life. Between the lives of 100 and 30,000 cycles, there is a very slight negative slope to the fatigue curves at any given temperature. The difference in maximum stress over this life range is approximately $100 \mathrm{MPa}$, indicating the flat nature of these curves. On the right of the graph are arrows depicting the range of UTS values for GMPX at each respective temperature. Note that the UTS values bracket the stress values from the fatigue tests at similar temperatures. Similar to the UTS values, the maximum fatigue stresses rank with temperature, with the smallest stresses being at $800{ }^{\circ} \mathrm{C}$. The Gamma Met 100 alloy has inferior fatigue strength due to its lower tensile strengths. A block of 
fatigue values in figure 9 represents data from a previous study (ref. 6) of a first-generation, cast TiAl alloy, Ti-47Al-2Cr-2Nb. These tests were conducted at $650{ }^{\circ} \mathrm{C}$ in load-control at $100 \mathrm{~Hz}$ and under zerotension loading. These data are also represented well by their tensile strength, but fall much lower than the other two Gamma alloys due to its lower UTS.

The initial $425{ }^{\circ} \mathrm{C}$ fatigue stress-strain curve was essentially elastic/perfectly plastic, figure 10 . The second cycle had much less plasticity per given stress range than observed in the first cycle due to hardening. Likewise, each successive cycle showed slightly less plasticity. However, even near failure, there was some plasticity in the cycles. It should be pointed out that with each cycle, the hysteresis loops shifted toward increasing tensile strains. This ratcheting is a result of inelastic strain accumulation due to the applied stresses. It is interesting to note that the ratcheting never shakes-down, suggesting that creep mechanisms are active even at $425^{\circ} \mathrm{C}$.

The fatigue fracture surfaces looked similar regardless of test temperature. All of the samples tested at $425{ }^{\circ} \mathrm{C}$ and below initiated at some type of machining damage. In most cases, these defects were pits from the EDM process. The fracture depth of the pits was typically less than $0.05 \mu \mathrm{m}$; however, these samples were polished before the test in an attempt to minimize the effect of the damage. Hence, the initial depth of the pits was deeper. Samples tested later in the program, those at 600 and $800{ }^{\circ} \mathrm{C}$, were sufficiently polished to remove any machining damage and these samples initiated randomly along the circumference of the fracture surface, figure 11. The initiation sites were easily observed at elevated temperatures due to the heat tinting on the fracture surface. The fatigue crack in figure 11 propagated by a flat Stage I type of mode approximately $80 \mu \mathrm{m}$ into the sample at which point it changed to a mixed mode of intergranular and cleavage fracture. No striations were observed in any sample. Polished samples revealed that the fatigue cracks traveled along the boundaries of gamma grains and through the $\gamma / \alpha_{2}$ lamellar colonies.

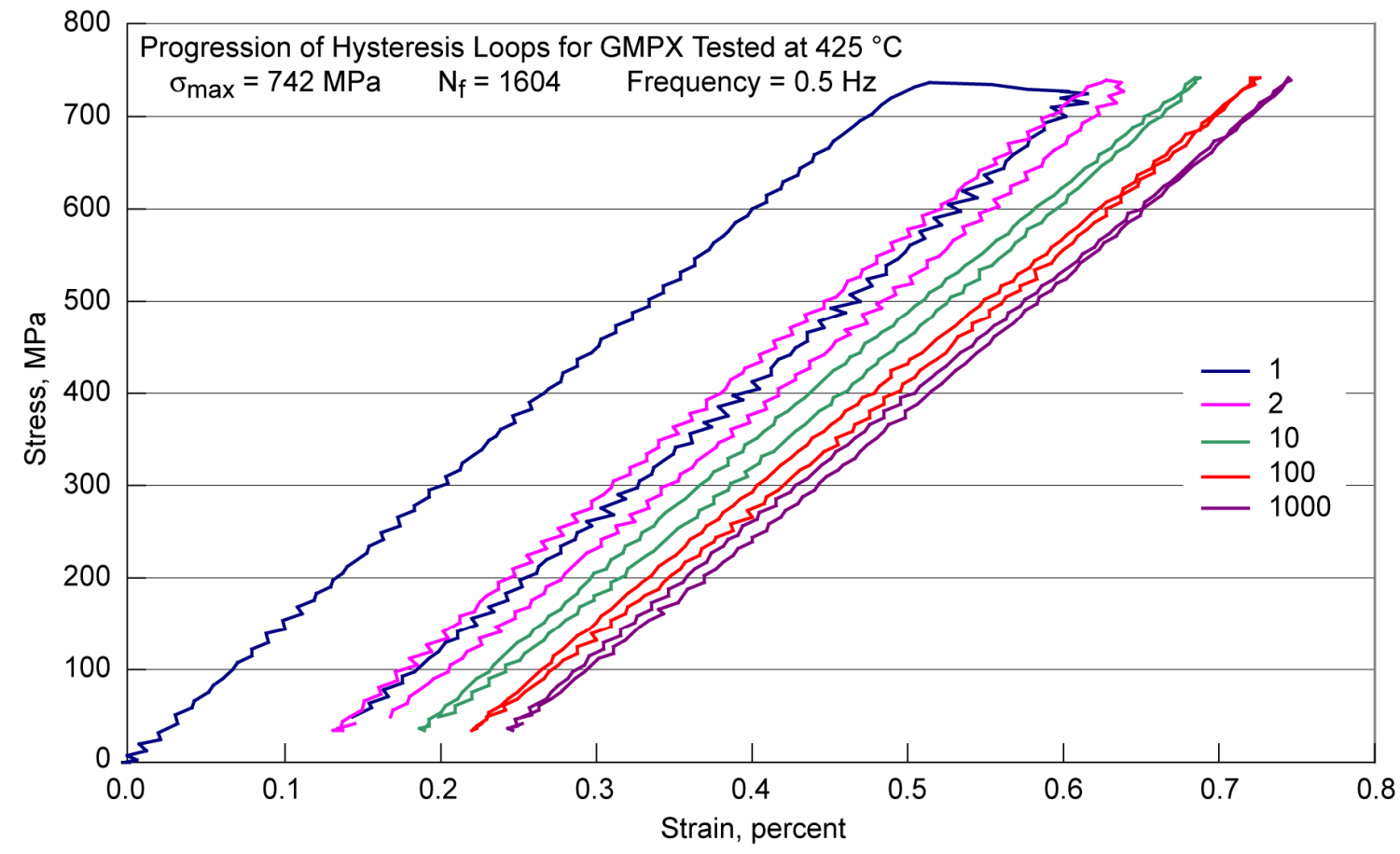

Figure 10.-Hysteresis loops for a $425^{\circ} \mathrm{C}$ load-controlled test with a maximum stress of $742 \mathrm{MPa}$ showing strain ratcheting. 


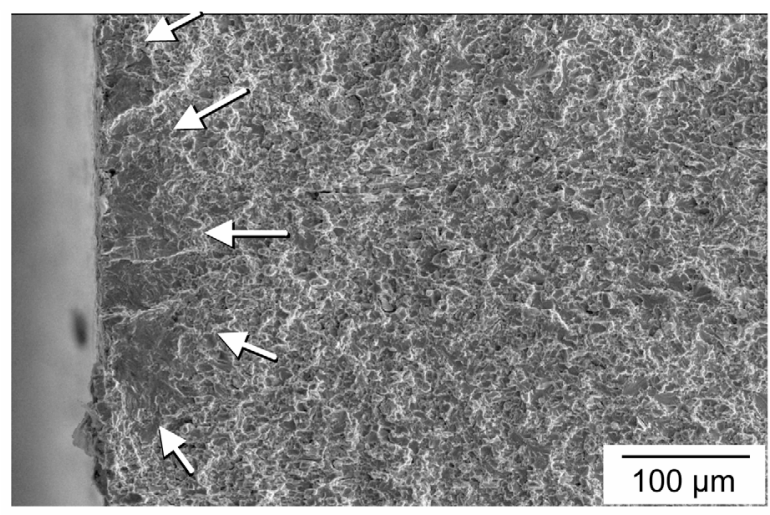

Figure 11.-Fracture surface of load-controlled fatigue sample tested at $425^{\circ} \mathrm{C}$. Arrows indicate initiation site.

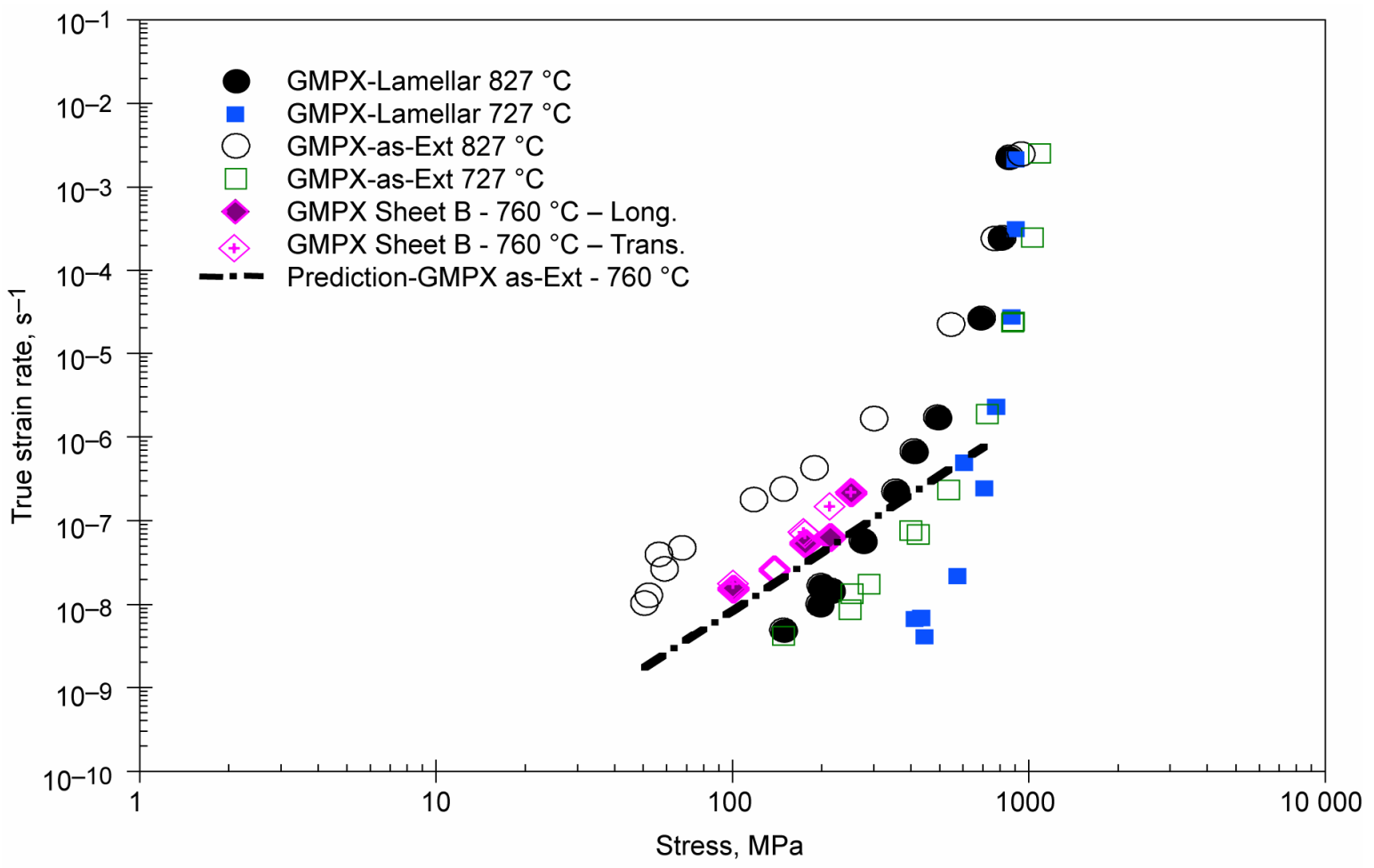

Figure 12.-Steady-state creep rate of GMPX sheet tested at $760^{\circ} \mathrm{C}$ as a function of stress is compared to the creep response of GMPX as-extruded rods and lamellar heat treated rods at various temperatures [4].

GMPX sheet samples were tested in tension creep at $760{ }^{\circ} \mathrm{C}$. Summary plots of the true steady-state strain rate $(\dot{\varepsilon})$ as a function of flow stress $(\sigma)$ are given in figure 12 for GMPX sheet and several conditions of GMPX extruded bar for comparison purposes (ref. 9). As-extruded and lamellar heat treated rod samples have nearly equivalent strengths at temperatures below $827^{\circ} \mathrm{C}$ and fast strain rates. However, at higher temperatures and slower strain rates, the lamellar heat-treated material is significantly stronger than the as-extruded alloy. In the low stress region, the compressive flow stress-strain rate properties were described by a temperature compensated power law relationship (ref. 9):

$$
\dot{\varepsilon}=A \sigma^{n} \exp (-Q / R T),
$$


where $A$ is a constant, $n$ is the stress exponent, $Q$ is the activation energy for deformation and $R$ is the universal gas constant. At high stresses, the power law breaks down and the data were not used to fit the equations. The as-extruded data fits the power law equation with a stress exponent of $2.1 \pm 0.1$ and an activation energy of $379.7 \pm 16 \mathrm{~kJ} / \mathrm{mol}$. Using equation (1), a creep prediction at $760{ }^{\circ} \mathrm{C}$ for the asextruded GMPX data appears to describe well the creep of the sheet material for the range of stresses studied. The creep behavior is comparable in the transverse and longitudinal directions.

The tensile strength of the highest strength GMPX sheet tested in this program, sheet GMPX-F $1 \mathrm{~mm}$, was comparable to the strength of GMPX extruded bar with a duplex microstructure (ref. 9). However, the tensile strength of the other four sheets was slightly lower than the extruded bar material as was the fatigue and creep strength (ref. 9). The fatigue strength of TiAl correlates with the ultimate tensile strength of the alloy such that the high tensile strength of GMPX results in significantly higher fatigue strength for GMPX than previous TiAl alloys. The mechanical properties of the sheet and extruded material were fairly comparable given the differences in the microstructures of the two materials. While both microstructures would be considered duplex, the extruded material had a nearly lamellar microstructure compared to the sheet's primarily gamma microstructure with lamellar colonies surrounding the gamma grains. The GMPX sheet was tested only in the duplex condition but a previous report correlates extruded material microstructure with mechanical properties (ref. 9). The creep strength of extruded GMPX is significantly improved by transforming the microstructure to fully lamellar but the lamellar microstructure results in lower tensile and fatigue strength (ref. 9). The microstructure utilized will depend on the application and which property is life limiting.

\section{Configuration Specific Coupon Tests}

Configuration-specific coupons were defined, fabricated, and structurally tested to assess key configuration features of the subelement. The specimens were utilized to assess stress concentrations, especially at steps, bolts, and braze joints, and the results were incorporated into the pretest and post-test subelement strength predictions. Four coupon configurations, braze shear, stepped tensile, bolted clevis, and braze peel were tested.

The braze shear sample, figure 1(a), was trapped in the middle of a two-part tool that is pulled apart, applying a shear load across the specimen's braze joint. The braze shear samples failed at average strengths of $317 \pm 76,365 \pm 90$, and $379 \pm 7 \mathrm{MPa}$ at 23,371 , and $650{ }^{\circ} \mathrm{C}$, respectively. The braze shear load-displacement curves were linear at 23 and $371{ }^{\circ} \mathrm{C}$, but a small amount of plasticity was observed for samples tested at $650{ }^{\circ} \mathrm{C}$, figure 13. The braze shear strengths obtained on GMPX were similar to strengths reported for Gamma Met 100 (ref. 7). All of the samples failed through the braze with a brittle fracture morphology and braze material remaining on both the rectangular piece and the disk.

The stepped tensile specimens, figure 1(b), were intended to have a $0.13 \mathrm{~mm}$ braze fillet in the corners where the $6.4 \mathrm{~mm}$ plate ended, however, the braze fillet was essentially zero. Additional stepped tensile specimens were fabricated using only $1 \mathrm{~mm}$ thick sheet due to lack of availability of $6.4 \mathrm{~mm}$ plate. Unfortunately, these additional samples also had little or no braze fillet in the corner regions. Two of the thicker samples were tested at $600{ }^{\circ} \mathrm{C}$ with $25 \mathrm{~mm}$ of each end inserted into water-cooled grips. The sample was positioned in the furnace such that the corner-fillet regions were both at $600{ }^{\circ} \mathrm{C}$. The room temperature samples had strengths ranging from 200 to $278 \mathrm{MPa}$ with total failure strains averaging only 0.09 percent. The stepped tensile specimens had slightly higher strength at elevated temperature with the UTS's averaging $352 \mathrm{MPa}$. All of the samples failed at the step region, with only the braze and the $1 \mathrm{~mm}$ sheet undergoing fracture. The braze exhibited a brittle fracture morphology, even at $600{ }^{\circ} \mathrm{C}$, figure 14 . ANSYS finite element studies were performed to determine the effective sharp corner theoretical stressconcentration factor $\left(\mathrm{K}_{\mathrm{t}}\right)$ for the stepped tensile specimens. Increasing braze radius had a predicted decrease in $\mathrm{K}_{\mathrm{t}}$. Using the stepped tensile test results along with minimum and maximum gamma TiAl strength, the range of effective Kt's possible for the square corner specimens tested was determined to be between 2.7 and 3.8. These $\mathrm{K}_{\mathrm{t}}$ 's are used in predicting the subelement strength at similarly loaded stepped features. 


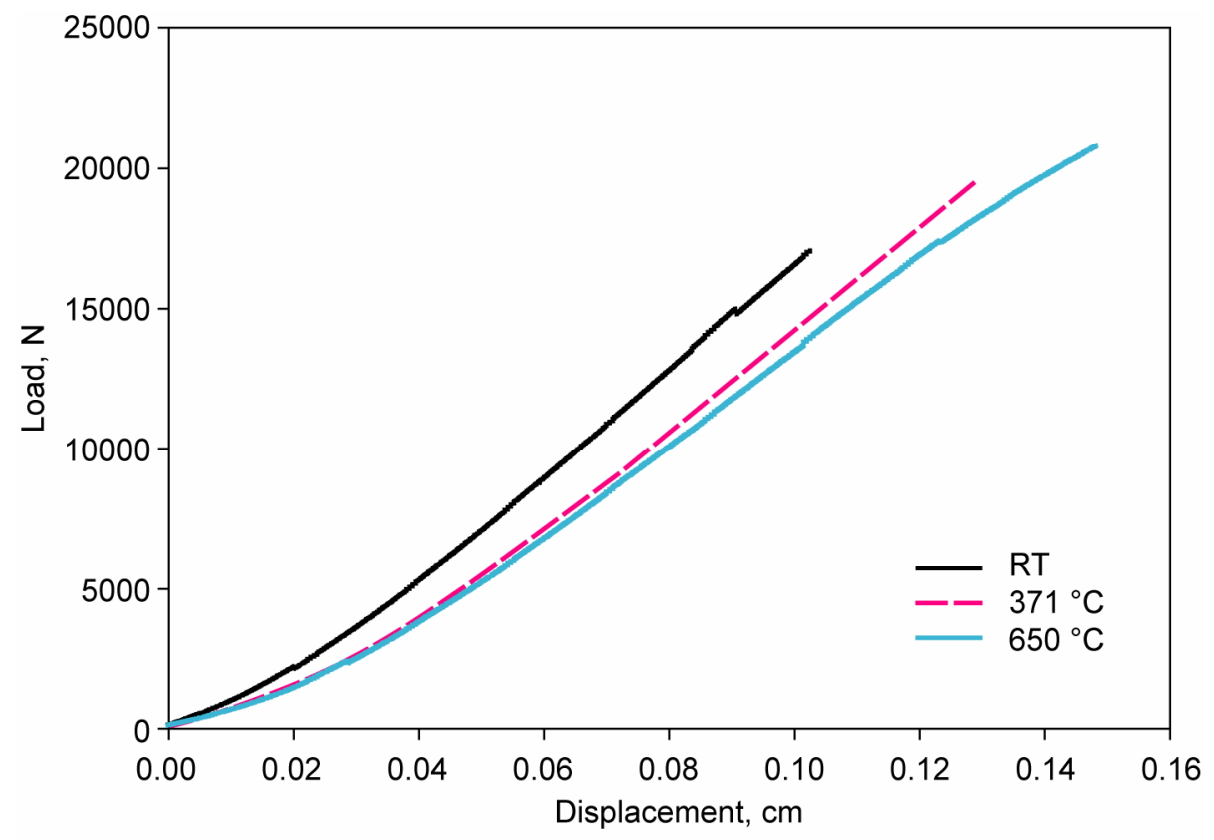

Figure 13.-Braze shear load displacement curves for RT, 371 , and $650^{\circ} \mathrm{C}$ tests.

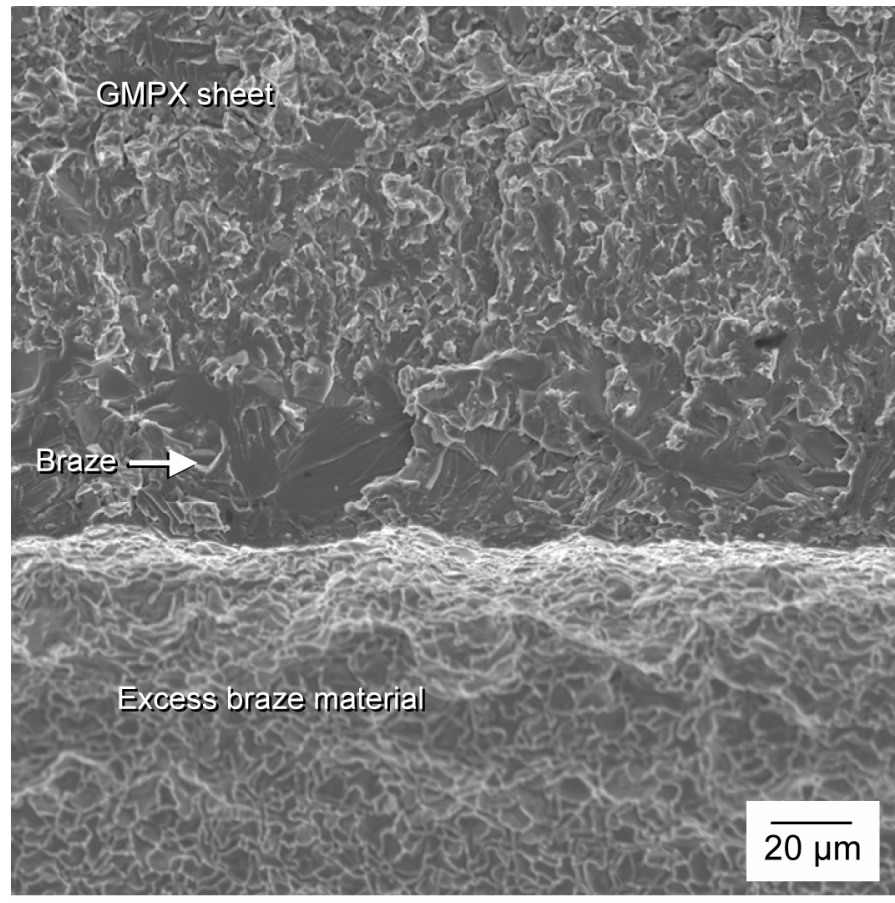

Figure 14.-600 ${ }^{\circ} \mathrm{C}$ stepped tensile fracture surface showing brittle fracture morphology of braze.

Three bolted clevis samples, figure 1(c), were tested at room temperature. The average failure stress was $90.3 \pm 46 \mathrm{MPa}$, significantly below the ANSYS predicted strength range of 190 to $240 \mathrm{MPa}$. All three samples failed, as expected, at one of the bolt holes at an intersection of a braze and the machined hole. One of the samples had an initiation site on both sides of the hole at the second bond line, explaining the lower strength of this sample. Brazes were easily observed on the fracture surface in the SEM due to their brittle fracture morphology, figure 15. Backscatter electron imaging (BSE) showed a 
lighter contrast at the bond line, indicating the braze chemistry had a higher atomic number. The low strengths of the bolted clevis samples and the observation of failures initiating at brazed joints indicated that the braze was a major contributor to the low strength. While the capability observed by these bolted clevis coupon tests is adequate for the subelement due to the design margin at this location relative to other more limiting features, the detrimental effect of having fasteners or other stress concentrations intersect a braze should be considered in subsequent designs.

The braze peel samples were fabricated by brazing four strips of $1 \mathrm{~mm}$ thick GMPX sheet together to form a cross configuration, figure 1(d). The samples were processed in a one-step brazing cycle with the long aspect laying flat and the short dimension undergoing a vertical braze. The quality of the braze was appraised by Plansee with samples 1, 2, 3, and 4 believed to have good brazes and selected for room temperature tests. Since the subelement was to be tested at room temperature, the room temperature configuration coupon tests were considered to be of higher importance. At room temperature, the samples failed between 275 and $490 \mathrm{~N}$ and at $760{ }^{\circ} \mathrm{C}$ the samples failed at 347 and $498 \mathrm{~N}$. While nearly equivalent strengths were obtained at room temperature and $760^{\circ} \mathrm{C}$, the high temperature samples had visibly inferior brazes. Therefore, determining the effect of high temperature on braze peel strength was impossible. A representative load-strain plot for each temperature is shown in figure 16. All of the samples failed in a noncatastrophic manner. After reaching the peak load, a drop in load gradually occurred indicating the braze peeling. One sample's braze failed completely across the short span, however, the remaining samples failed from a crack propagating through the GMPX sheet, approximately $3 \mathrm{~mm}$ from the center of the sample, on one or both sides of the short span. The strain gages on opposing sides of the samples recorded non-uniform strains during the room temperature tests, indicating one side of the braze peeled more readily than the other side. The uneven distribution of strain resulted in an additional tensile stress, promoting crack propagation through the GMPX sheet. The extensometer
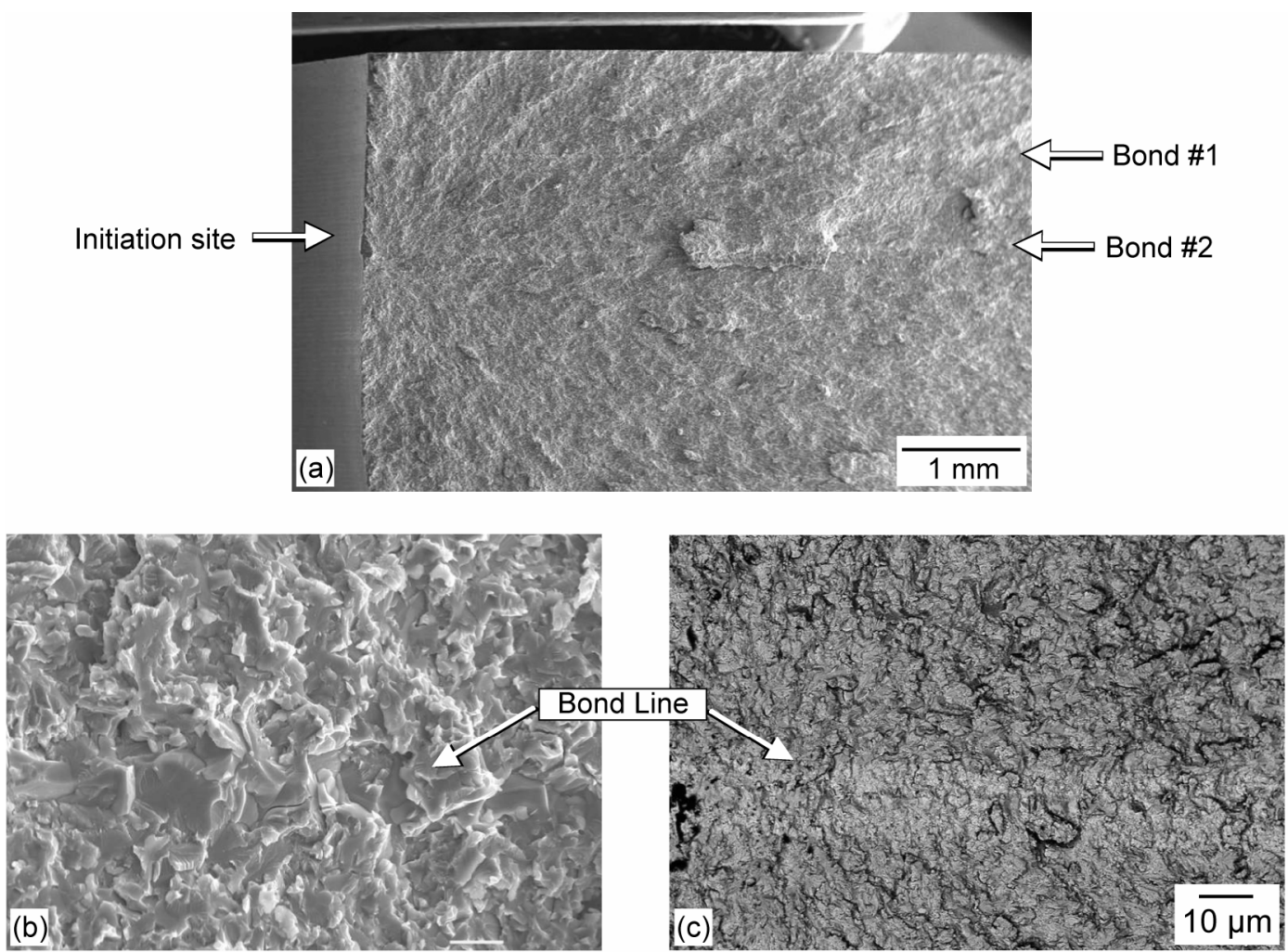

Figure 15.-(a) Bond lines are easily visible on fracture surfaces of bolted clevis samples. (b) Brittle fracture morphology is observed at the bond line of bolted clevis samples. (c) Backscatter electron images show bond having a higher atomic number compared to Gamma Met PX. 


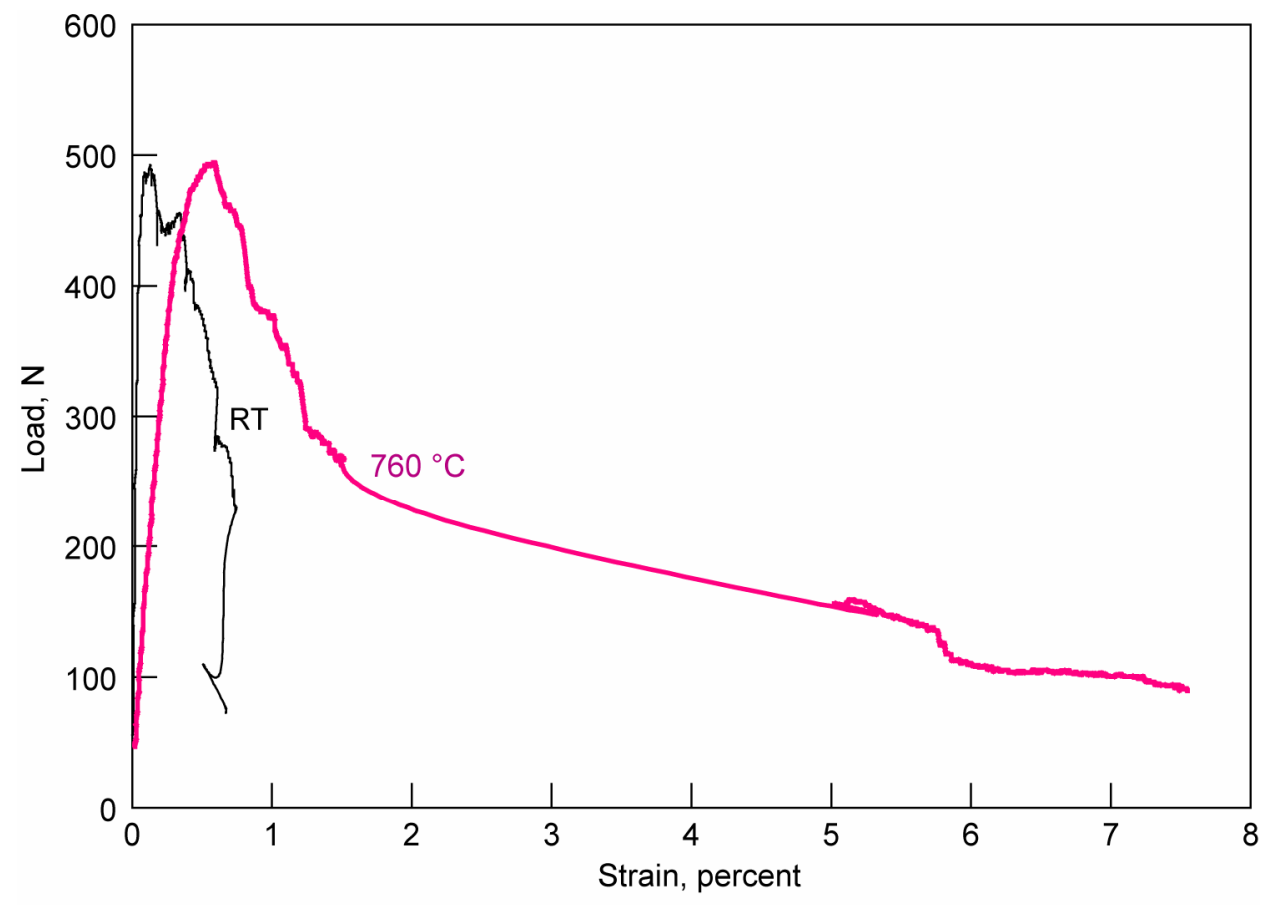

Figure 16.-Representative braze peel load-strain curves at RT and $760{ }^{\circ} \mathrm{C}$. Strain was measured from an axial extensometer, which spanned the braze joint.

bridged the braze joint such that the considerable amount of elongation due to the separation of the braze was included while the strain gages recorded only the small amount of elastic strain which accumulated in the TiAl sheet, less than 0.01 percent. The average room temperature peel strength was calculated to be $157 \mathrm{~N}$ per linear $\mathrm{cm}$ of braze line. Thus, the design load for these types of subelement joints were based on these test results. Loads exceeding this value would likely locally peel the braze interface incrementally until the local GMPX sheet bending stress exceeded the material strength.

\section{Braze Characterization}

Samples containing brazes from the subelement, bolted clevis, and braze peel samples were examined utilizing backscatter electron imaging in a SEM, figure 17. The braze layers were very distinctive with sharp boundaries between the sheet microstructure and the braze region. The thickness of the braze, while relatively consistent, did vary with sample configuration. The narrowest braze observed, at $75 \mu \mathrm{m}$, was a horizontal braze in the subelement close to a bolt hole. However, another horizontal braze in the subelement, at the bottom of a C-channel, was a more typical $119 \mu \mathrm{m}$ in thickness. The majority of the brazes are symmetrical with large globular grains containing nearly equivalent atomic concentrations of $\mathrm{Ti}, \mathrm{Ni}$, and $\mathrm{Al}$ in the center surrounded by $\mathrm{Ti}_{3} \mathrm{Al}$ grains, which had slightly higher concentrations of $\mathrm{Al}$ and $\mathrm{Nb}$, figure 17. The braze region was higher in $\mathrm{Ti}$ and lower in $\mathrm{Al}$ and $\mathrm{Nb}$ in comparison to the base alloy. Ni was not detected by EDS analysis outside of the braze region. In a few braze regions, small areas of eutectic microstructure which contained a Ti-Ni-Al phase and $\mathrm{Ti}_{3} \mathrm{Al}$ were observed. 

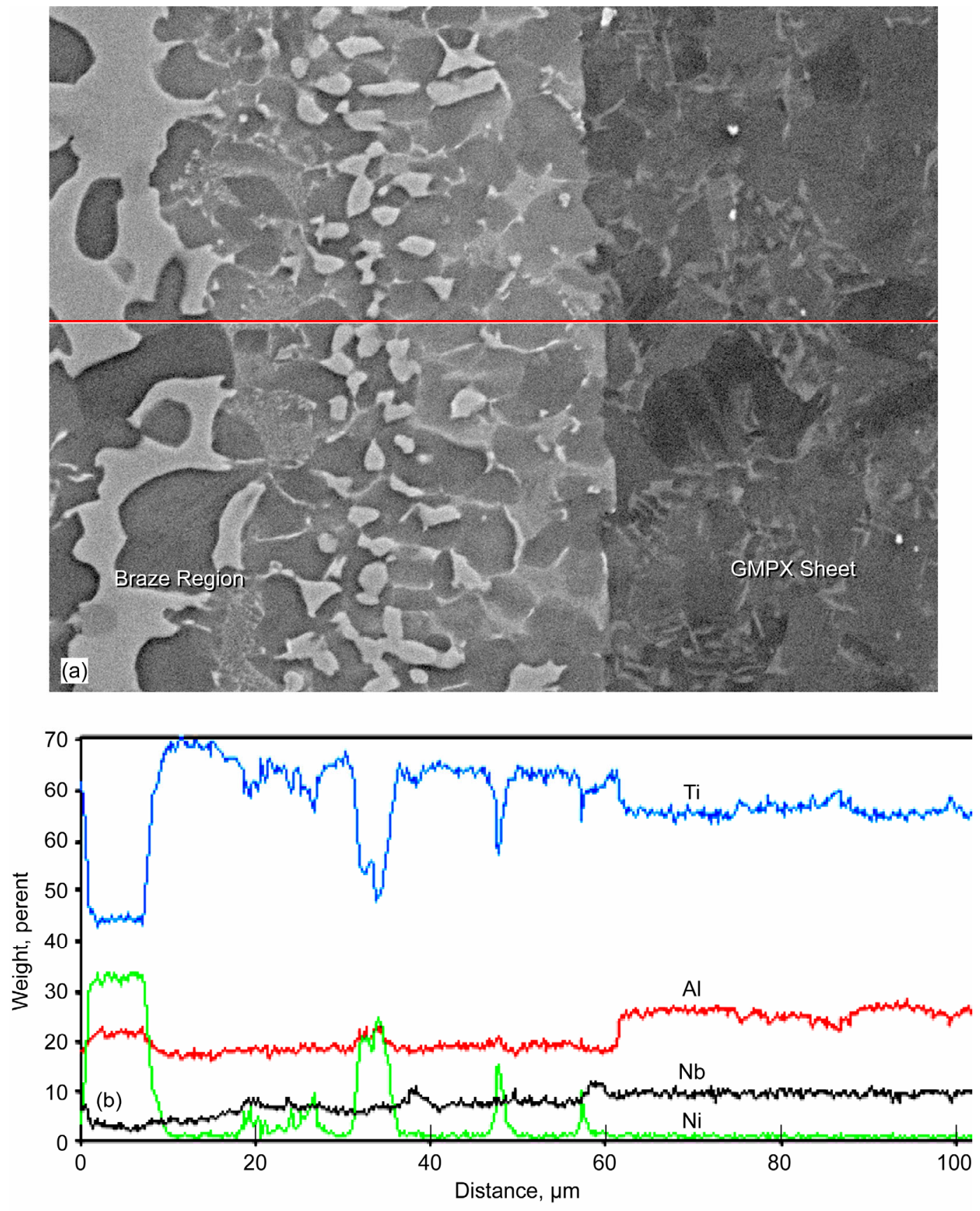

Figure 17.-(a) BSE image and (b) corresponding EDS line scan for $\mathrm{Ti}, \mathrm{Al}, \mathrm{Nb}$, and $\mathrm{Ni}$ going from middle of braze to GMPX sheet.

\section{E. Subelement Test Predictions and Results}

The subelement test was designed to simulate the limiting load condition during the inlet flap operation, specifically a cantilever load at the flap hinge. Finite Element Analysis (FEA) was used for subelement test failure load prediction and evaluation of test results. All nonbrazed interfaces were modeled using three dimensional point-to-point contact elements. Braze interfaces were modeled by merging adjacent nodes except between the face sheets and C-channels where all degrees-of-freedom were coupled. Coupling was done at this particular braze location to allow the ability of locally detaching the interface in an effort to simulate the braze peeling. At $8889 \mathrm{~N}(2000 \mathrm{lb})$ load, the left and right flange 
strain gages indicated different stress values. The half of the subelement which was modeled (the failure initiation side) had slightly higher than expected stress (49.3 MPa) while the opposite side flange strain gages were reading low by approximately the same amount (42.5 MPa). When these left and right flange strain gages were averaged, the ANSYS predicted stresses matched the measured test results within 2 percent. Based on these measurements, it was concluded that during test set-up a slight vertical misalignment occurred between the load frame load line and the subelement bar. This caused slightly more load to be applied to the modeled side of the subelement. The overall effect is a 9 percent higher test stress on the failure side of the subelement. Strain gage response was linear with load throughout the subelement test. Based on strain gage readings, the subelement FEA stress predictions closely match actual test measurements at the described instrumented locations. Front surfaces of the subelement were coated with a high contrast random painted pattern for use in two-dimensional speckle pattern interferometry (SPI) system. This method employs pattern recognition of the painted area to calculate strains from displacements. Because the surface of the subelement at the key high stress braze locations was irregular, the results of the SPI system were inconclusive.

Since the braze peel specimens were not tested before the subelement test, pretest predictions were made using experience gained from the bolted clevis and stepped tensile coupons. The FEM mesh density was set to minimize the possibility of modeling stress concentrations so ANSYS element stress (not nodal) results could be considered near nominal stress values. A Kt approach was used to predict failure. Based on bolted clevis test results and ANSYS results, there was little risk of failure near the bolt attachments. The limiting location was predicted to be on the lower face sheet and C-channel flange at the end of the subelement nearest to the load frame, figure 18. The subelement design specified a braze connection at the interface area between the C-channel and stiffener. Although all other features and aspects of the subelement construction appeared excellent, this area had a lack of braze (a piece of paper could be slipped in between the two pieces of this intended bond joint). As a result, the subelement overall capability was reduced.

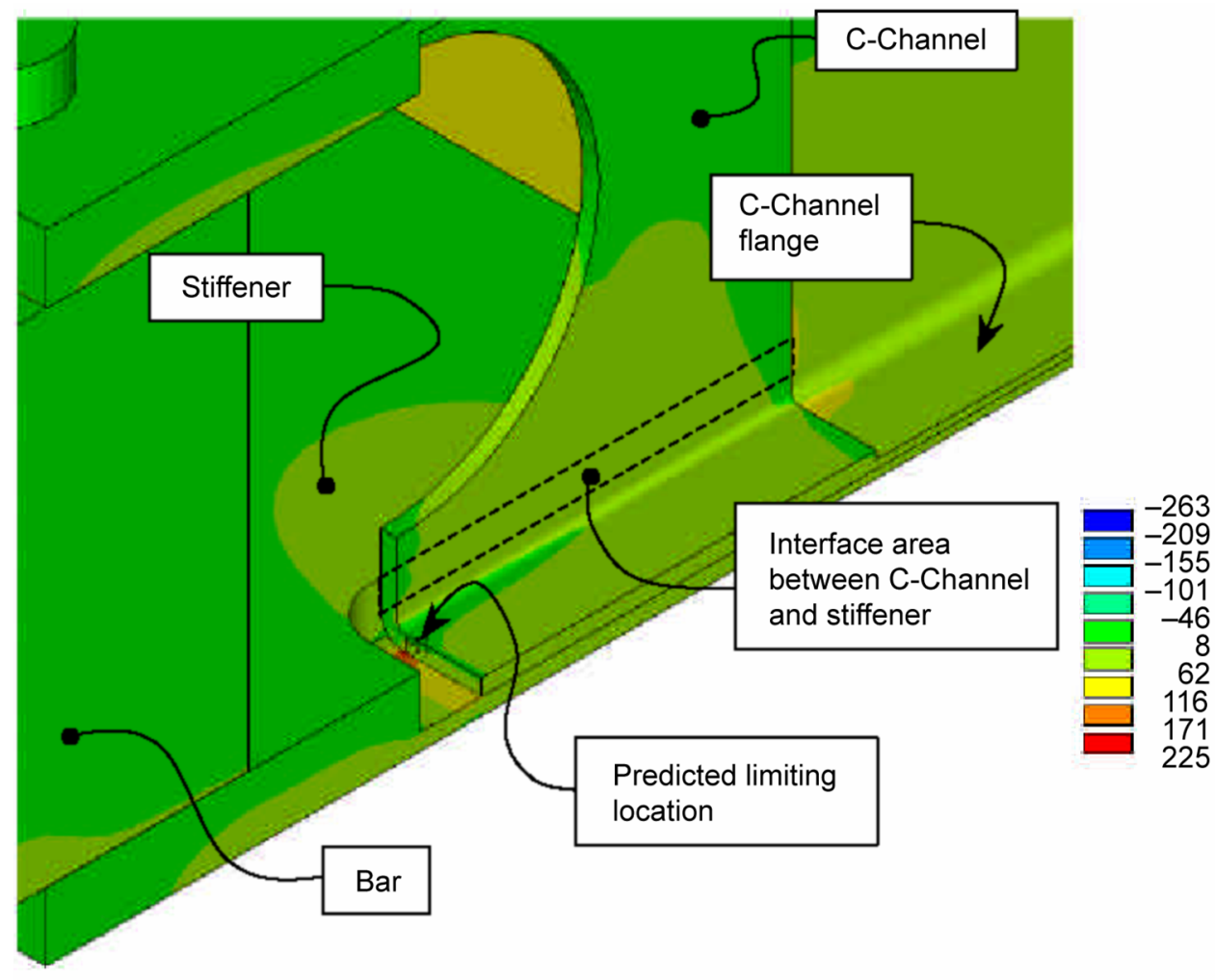

Figure 18.- Illustration of subelement maximum stress (in MPa) location and predicted limiting location. 


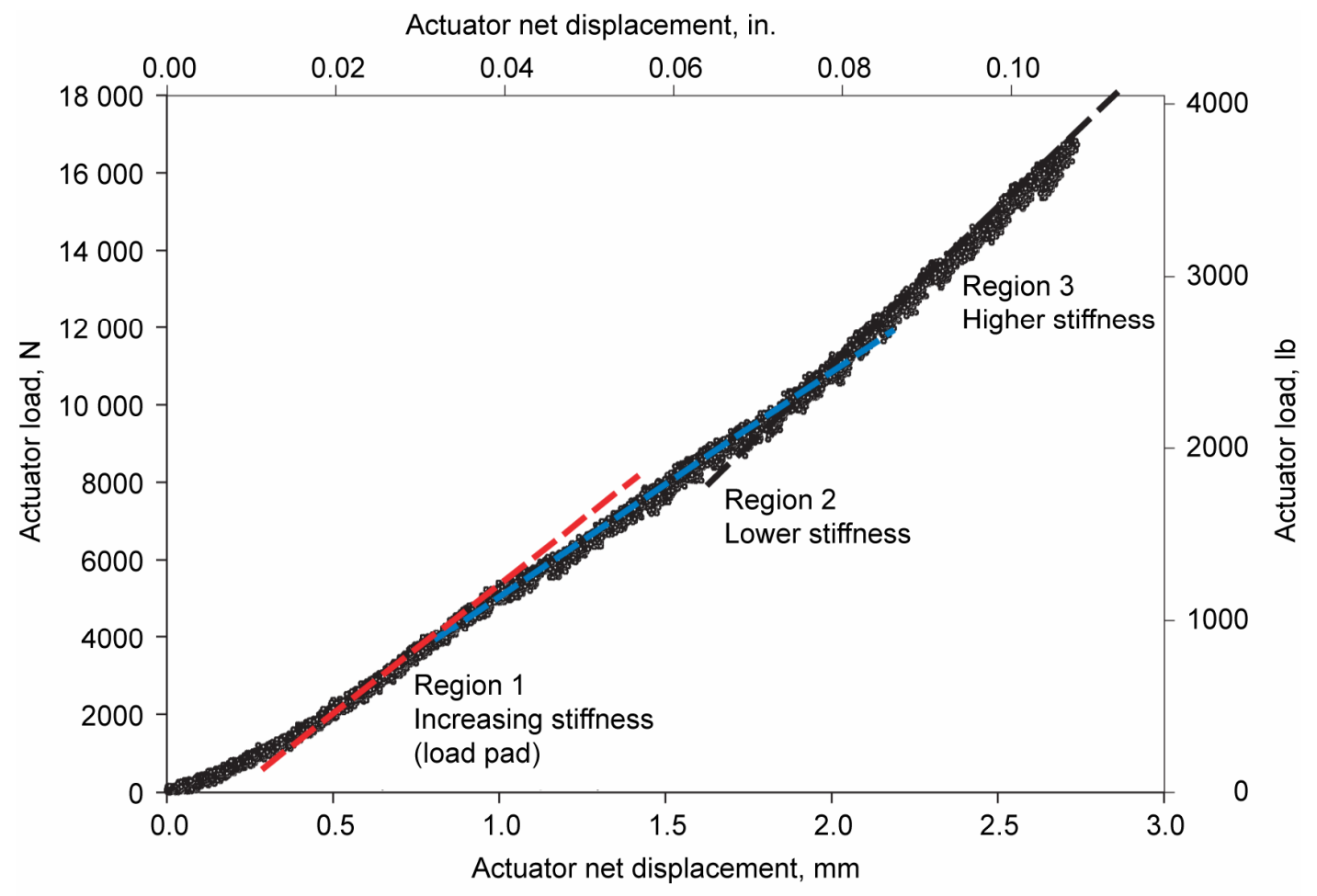

Figure 19.-_Subelement load and displacement test results.

The subelement was predicted to fail between 3778 and $11111 \mathrm{~N}(850$ to $2500 \mathrm{lb})$ depending on the actual material UTS ( 820 to $1140 \mathrm{MPa}$ ) and range of possible stress concentration factors (2.7 to 3.8 ). However, the subelement failed at a substantially higher applied load of $16915 \mathrm{~N}$ (3806 lb), figure 19. During the subelement test, the applied load was increased in small increments. After each load addition, strain gage readings were recorded. The different stiffness regions shown in figure 19 are attributed to the nonlinear behavior of the rubber load pad between the load frame and the test specimen. The subelement separated into three pieces at failure, figure 20(a).

Post-test examination indicated that a likely scenario for failure initiation was braze peel at the predicted location between the lower face sheet and C-channel flange, figure 20(b). During the incremental load application, various intensities of cracking sounds were audible. The first cracking sound occurred at a force of $2222 \mathrm{~N}(500 \mathrm{lb})$. Another cracking sound was recorded at $4889 \mathrm{~N}(1100 \mathrm{lb})$, and cracking sound became frequent and regular from $6222 \mathrm{~N}(1400 \mathrm{lb})$ through failure. Several visual checks were done during the test and surface cracks were not found. It is theorized that the cracking sounds during the test were the sounds caused by braze joints failing in peel mode.

Since the pretest predictions were quite conservative relative to the actual measured failure load, more analysis was performed to better understand how the subelement withstood a test force substantially greater than the highest pretest prediction. Subsequent braze peel tests showed that a typical braze joint similar to the subelement joint failure site would be expected to separate at a peel load of $157 \mathrm{~N}$ per linear $\mathrm{cm}$ of braze line. ANSYS model predictions showed that at a test load of $1778 \mathrm{~N}$, the line load at the failure site would equal $157 \mathrm{~N}$ per linear $\mathrm{cm}$ based on the nearly uniform load distribution of the first $1.9 \mathrm{~cm}$ of braze line. Thus, once the subelement applied load exceeded $1778 \mathrm{~N}$, the joint would begin to separate by braze peel. Since joint peeling would tend to reduce the C-channel vertical stiffness, causing a reduction in the peel load, the peel load would be self-limiting and the peel process would stop until additional load was applied. The predicted $1778 \mathrm{~N}$ test load at peel initiation compares well with the initial cracking sound recorded at $2222 \mathrm{~N}$ during the subelement test. Analysis shows that by peeling, local stresses in the facesheet and C-channel were reduced as the subelement load was increased. Next the peel separation crack front progresses across the braze joint in a direction toward the outer edges of the 
subelement until the $\mathrm{C}$-channel flange bending stress exceeds the material capability. During the braze peel tests, it was noted that the parent material failed after "unzipping" approximately one-half of the joint width. At $157 \mathrm{~N}$ per linear cm, the nominal bending stress would be approximately $579 \mathrm{MPa}$ based on the average peel test results. The ANSYS results were processed to eliminate potential modeling Kt effects by unselecting unwanted elements and conducting a stress linearization through the limiting section. At a test load of $8889 \mathrm{~N}(2000 \mathrm{lb})$, the membrane and bending stress was a maximum at the bottom of the Cchannel at $343 \mathrm{MPa}$. Using the $579 \mathrm{MPa}$ allowable from the peel coupon test, the ANSYS loading can be scaled $(579 / 343=1.69)$. Scaling the applied load by 1.69 results in a predicted failure load of $15022 \mathrm{~N}$. The subelement actually failed at $16915 \mathrm{~N}$, approximately 13 percent higher than the ANSYS predictions.
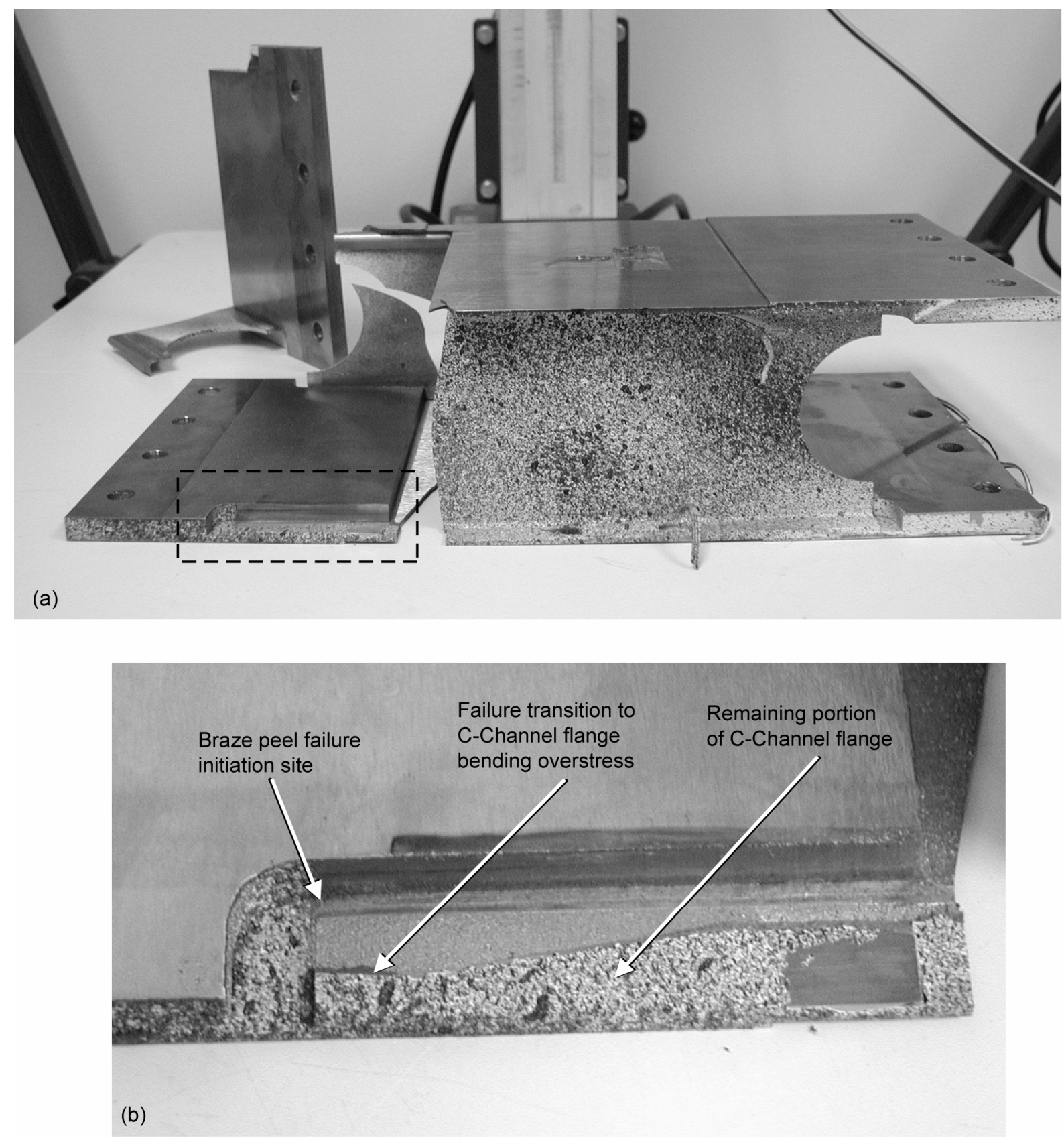

Figure 20.-(a) Subelement separated into 3 pieces upon failure. (b) Close-up view of failure initiation site (boxed area in figure 20(a). 


\section{Summary and Conclusions}

TiAl sheet has many potential aerospace applications due to it's attractive properties. However, TiAl sheet is challenging to manufacture and has not been commercialized. Five GMPX sheets, among the first sheet produced, were obtained for characterization in this program. While all of the GMPX sheets had a duplex microstructure, two of the sheets had lamellar colonies with very fine lamellar spacing. Unfortunately, the microstructure could not be consistently correlated with the tensile properties of the sheet. Microstructural inconsistencies occasionally lowered the ultimate tensile strength and ductility of the sheet. Additional sheet characterization is required to accurately determine sheet-to-sheet variations in mechanical properties. Electrolysis free EDM followed by low stress grinding resulted in the best machining for mechanical test samples. The fatigue strength of TiAl correlates with the ultimate tensile strength of the alloy such that the high tensile strength of GMPX results in significantly higher fatigue strength for GMPX than previous TiAl alloys.

The configuration-specific coupon tests provided invaluable data for the design system as they determined the effect of key configuration features, such as steps, bolts, and brazed joints, on the performance of the subelement when loaded. However, the results of the coupon tests were below expectations. Based on prior experience, brazing was selected as the joining technique for the subelement and therefore the realistic feature test coupons were also joined by brazing. All of the configurationspecific coupons failed at the braze with the braze exhibiting a brittle failure morphology. The brittle braze fracture morphology suggests this braze would have little ability to redistribute stress concentrations. Thus, careful judgment is needed when assuming design capabilities based on average stress calculations. The development of a joining technique, which is not detrimental to the mechanical properties of GMPX sheet, is critical and future research should focus on joining techniques which could be utilized for large structures.

Three subelements were fabricated with excellent dimensional tolerance. The subelement test predictions based on finite element analysis matched well with the actual subelement test results. The model predicted initial cracking starting at $1778 \mathrm{~N}$ and the first audible cracking sounds, believed to be due to the braze joints failing in peel mode, started at $2222 \mathrm{~N}$. Ultimate failure of the subelement was predicted within 13 percent of the actual failure load. While the subelement was designed to have excess capability at the bolt holes, the detrimental effect of fasteners or other stress concentrations intersecting a braze should be considered in subsequent designs. Significant progress on the design, fabrication, analysis, and testing of TiAl structural components was achieved.

\section{References}

1. C. Collier: Informal Program Review, NASA Contract NAS3-01138, task order 11, Nov. 2002.

2. F. Appel, U. Lorenz, J.D.H. Paul, M. Oehring, Gamma Titanium Aluminides 1999, Y.W. Kim, D.M. Dimiduk, M.H. Loretto (Eds.), TMS, Pennsylvania, 1999, pp. 381-388.

3. F. Appel, J.D.H. Paul, M. Oehring, and C. Buque, Gamma Titanium Aluminides 2003, Y.W. Kim, H. Clemens, and A.H. Rosenberger (Eds.), TMS, Pennsylvania, 2004, pp. 139-151.

4. S.C. Huang and D.S. Shih, Microstructure/Property Relationships in Titanium Aluminides and Alloys, Y.W. Kim and R.R. Boyer (Eds.), TMS, Pennsylvania, 1991, pp. 105-122.

5. Y.W. Kim, Intermetallic Alloys Based on Gamma Titanium Aluminide, JOM, vol. 41, no. 7 (1989), pp. 24-30.

6. S.L. Draper, B.A. Lerch, J.M. Pereira, K. Miyoshi, V.K. Arya, and W. Zhuang: Durability Assessment of Gamma TiAl- Final Report, NASA/TM-2004-212303.

7. EPM Annual Report, Vol. 3: Task B-Exhaust Nozzle, NASA Contract NAS3-26385, FR22596-4, pp. 104, Nov. 1998. 
8. S.L. Draper, B.A. Lerch, I.E. Locci, M. Shazly, V. Prakash, Effect of Exposure on the Mechanical Properties of Gamma Met PX, Intermetallics 13 (2005) pp. 1014-1019.

9. S.L. Draper, G. Das, I. Locci, J.D. Whittenberger, B.A. Lerch, and H. Kestler, Gamma Titanium Aluminides 2003, Y.W. Kim, H. Clemens, and A.H. Rosenberger (Eds.), TMS, Pennsylvania, 2004, pp. $477-483$. 


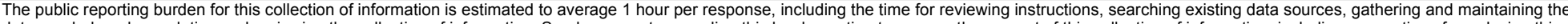

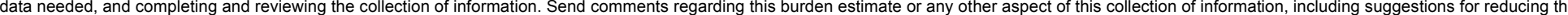

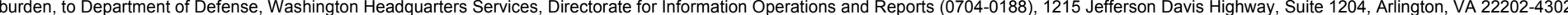

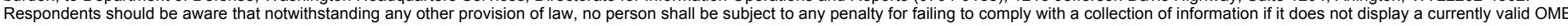
control number.

PLEASE DO NOT RETURN YOUR FORM TO THE ABOVE ADDRESS.

\section{REPORT DATE (DD-MM-YYYY) \\ 2. REPORT TYPE \\ 3. DATES COVERED (From - To)}

01-10-2007

\section{TITLE AND SUBTITLE}

Technical Memorandum

Development and Evaluation of TiAl Sheet Structures for Hypersonic Applications

5a. CONTRACT NUMBER

5b. GRANT NUMBER

5c. PROGRAM ELEMENT NUMBER

\section{AUTHOR(S)}

Draper, S., L.; Krause, D.; Lerch, B.; Locci, I., E.; Doehnert , B.; Nigam, R.; Das, G.; Sickles,

P.; Tabernig, B.; Reger, N.; Rissbacher, K.

\section{5d. PROJECT NUMBER}

\section{5e. TASK NUMBER}

5f. WORK UNIT NUMBER

WBS 599489.02.07.03.06

\section{PERFORMING ORGANIZATION NAME(S) AND ADDRESS(ES)}

National Aeronautics and Space Administration

\section{PERFORMING ORGANIZATION}

REPORT NUMBER

John H. Glenn Research Center at Lewis Field

E-15759-1

Cleveland, Ohio 44135-3191

\section{SPONSORING/MONITORING AGENCY NAME(S) AND ADDRESS(ES)}

National Aeronautics and Space Administration

Washington, DC 20546-0001

\section{SPONSORING/MONITORS ACRONYM(S) \\ NASA \\ 11. SPONSORING/MONITORING REPORT NUMBER \\ NASA/TM-2006-214467-REV1}

\section{DISTRIBUTION/AVAILABILITY STATEMENT}

Unclassified-Unlimited

Subject Category: 26

Available electronically at http://gltrs.grc.nasa.gov

This publication is available from the NASA Center for AeroSpace Information, 301-621-0390

\section{SUPPLEMENTARY NOTES}

This printing, numbered as NASA/TM-2006-214467/REV1, October 2007, replaces the previous version, NASA/TM-2006-214467, November 2006, in its entirety.

\section{ABSTRACT}

A cooperative program between the National Aeronautics and Space Administration (NASA), the Austrian Space Agency (ASA), Pratt \& Whitney, Engineering Evaluation and Design, and Plansee AG was undertaken to determine the feasibility of achieving significant weight reduction of hypersonic propulsion system structures through the utilization of TiAl. A trade study defined the weight reduction potential of TiAl technologies as 25 to 35 percent compared to the baseline Ni-base superalloy for a stiffener structure in an inlet, combustor, and nozzle section of a hypersonic scramjet engine (ref. 1). A scramjet engine inlet cowl flap was designed, along with a representative subelement, using design practices unique to TiAl. A subelement was fabricated and tested to assess fabricability and structural performance and validate the design system. The TiAl alloy selected was Plansee's third generation alloy Gamma Met PX (Plansee AG ), a high temperature, high strength $\gamma$-TiAl alloy with high Nb content (refs. 2 and 3). Characterization of Gamma Met PX sheet, including tensile, creep, and fatigue testing was performed. Additionally, design-specific coupons were fabricated and tested in order to improve subelement test predictions. Based on the sheet characterization and results of the coupon tests, the subelement failure location and failure load were accurately predicted.

\section{SUBJECT TERMS}

Titanium aluminides; Mechanical properties; Design analysis; Joining; Sheet; Structural design; Performance prediction;

Microstructure; Creep strength; Fatigue life

\begin{tabular}{|c|c|c|c|c|}
\hline 16. SECURI7 & ASSIFICATION & & 17. LIMITATION OF & 18. NUMBER \\
\hline $\begin{array}{l}\text { a. REPORT } \\
\text { U }\end{array}$ & $\begin{array}{l}\text { b. ABSTRACT } \\
U\end{array}$ & $\begin{array}{l}\text { c. THIS } \\
\text { PAGE } \\
\text { U }\end{array}$ & UU & $\begin{array}{c}\text { PAGES } \\
27\end{array}$ \\
\hline
\end{tabular}

19a. NAME OF RESPONSIBLE PERSON
STI Help Desk (email:help@ sti.nasa.gov)
19b. TELEPHONE NUMBER (include area code)
301-621-0390



